\title{
Air Quality Forecasting
}

\section{for Australia's Major Cities}

3rd Progress Report

\author{
Prepared by Project Management Committee \\ Chair: Dr Peter Manins \\ CSIRO Atmospheric Research \\ PMB 1 Aspendale 3195 \\ Australia

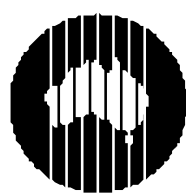 \\ CS I RO
}

Contact: peter.manins@ dar.csiro.au

10 April 2000 
Reference: PSS dh79

10 April 2000

The Director

Air Quality Section

Environment Protection Group

Environment Australia

The Administrative Build ing

King Edward Terrace, Parks ACT 2600

Attention Mr Paul Kesby

Dear Mr Kesby,

\section{Re: Air Quality Forecasting for Australia's Major Cities — Third Progress Report}

We are pleased to present the third progress report for the Australian Air Quality Forecasting System. The report is a compilation of progress reports for each of the four collaborating organisations for the project and managed by CSIRO Atmospheric Research.

\section{Introduction}

The project team comprises:
Environment Protection Authority (Victoria)
Environment Protection Authority of N SW
Bureau of Meteorology Research Centre
CSIRO Energy Technology and
CSIRO Atmospheric Research

A description of the Project, its management structure and the work schedule are described in the Appendix immediately following the Main Reports.

\section{Progress}

This Report essentially indicates progress to Phase 3, covering work to extend the real-time emissions inventory to Sydney, incorporating the new power-based vehicle emissions application, and verifying the full prototype system in Sydney. Some work in meeting objectives listed for Phase 4 is also reported, as is an aspect of Phase 5.

Progress has been mixed but overall very pleasing. The following sections summarise this. Appended, following a description of the Project overall, is an additional paper discussing 
performance of the meteorological component on a case study for Melbourne in December 1998. It complements the discussion of verification of the meteorology in the main report.

The following highlights are especially interesting:

- Emissions inventory modules are being developed for the on-line model, but delays have set back the completion of the biogenic emissions component somewhat.

- The power-based modelling of motor vehicle emissions has progressed substantially.

- After many improvements to the meteorological model, recent work has concentrated on validation. Studies of events in December 1998 for both Melbourne and Sydney have shown very pleasing performance by the model. A conclusion drawn is that at the fine scales being used for the Air Quality Forecasting System, there is a need for better initialisation of the meteorology forecasting.

- The first testing of the air chemistry module has been undertaken. Comparison of the high speed Generic Reaction Set (GRS) mechanism against observations and a much slower and more accurate $\mathrm{Carbon}$ Bond IV mechanism has highlighted emerging problems with forecasting to suburb scales:

- Small errors in timing and location of a pollution event lead to big changes in predictions at a particular location.

- Nevertheless, the air pollution component is progressing very well.

\section{Project Developments}

- The web site for the AAQFS has been running for some time and Environment Australia has had access for approximately a month.

- As a guest of Environment Australia, on 28 January I gave a presentation to the Air Managers' Forum on the Air Quality Forecasting System. It was very well received, attracting a lot of interest, even from those who were already quite familiar with the project.

- Delays with finalising contracts between CSIRO and Bureau of Meteorology, EPA Victoria and EPA NSW are beginning to have impact on the project. These need to be in place before the EPAs can agree on what materials on the Web site can be opened to the public. EA is also constrained in what can be publicised as well.

- Our external reviewer, Dr Phillip Morgan, DEP, Western Australia, has expressed his satisfaction with progress so far and the quality of the work being done. He has also made some observations on the inclusion of fine particles. His letter, dated 3 November 1999 , immediately follows this page.

- We continue to be on track to delivering a quality product for demonstration during the Olympic Games.

For and on behalf of

AAQFS Management Committee

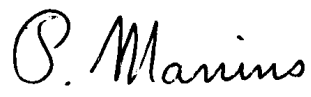

(Dr) Peter Manins PSM, FTSE, CCM, QEP 


\section{COMMENTS ON PROJECT FOR AIR QUALITY FORECASTING FOR AUSTRALIAN MAJOR CITIES}

I have read through Progress Reports 1 and 2 of this project and 1 am impressed with the progress made to date with this project. I regret that I am not able to attend the next Steering Committee meeting in Sydney to hear the discussion on progress with each component of the project.

The scope of the project indicates that this is a demanding and ambitious project, which will deliver considerable benefits for environment agencies if it can be successfully completed for all the large cities of this country. My understanding is that the primary focus is on quantitative forecasting of maximum concentrations of photochemical smog, at least in the first instance, and, presumably, PM10 later. I take it that this is the case because modelling skills are most advanced in this area, but I am also aware that modelling of thoracic particulate matter, ie PM10, has advanced to a fairly high skill level also.

Given the requirements of the contract with Environment Australia, I believe that the project is proceeding in probably the most appropriate manner. The extent of progress reported in Reports No 1 and No 2 was most encouraging for the success of the overall project. Even the AAFQ S trial, which indicated some problems to be overcome, was successful from an environmental management point of view.

With regard to the ultimate objective of the project, it might be helpful to keep in mind that, while scientific professionalism demands that simulations represent the actual as closely as possible, environmental management often accepts a reasonable concurrence between prediction and actuality. This reasonable concurrence is generally sufficient to justify issuing an alert or imposing a management action to reduce emissions. The balance between the higher demands of the science and the less stringent requirements of justifying management intervention should be borne in mind, as it may enable the science to provide a good approximation in the first instance and so allow a project deadline to be met. The modular nature of the components of the project might allow for refinements to be incorporated at a later stage.

The project is certainly providing important tools for air quality management. However, I have no doubt that all the participants are aware that urban haze has emerged as the key air quality issue needing resolution. Urban haze would seem to include both fine particulate pollution, the size range of 0.1 to 2 micrometres is usually cited, and oxides of nitrogen, plus some secondary aerosols. I imagine that modelling the finer particulate size ranges and secondary aerosols on a real time forecast basis might present some as yet unresolved challenges.

I have included these final comments merely to indicate that, over the time scale of the project, additional outcomes of this project may be sought. The project may need to be extended to develop haze forecasts once the current tasks have all been completed.

Phil Morgan

3 November 1999 


\section{Table of Contents}

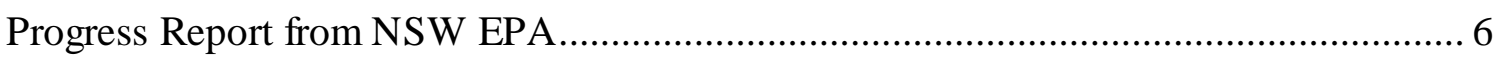

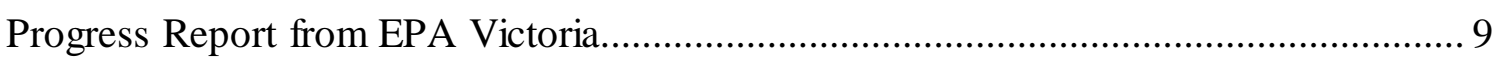

Progress Report from CSIRO Energy Technology ............................................... 13

Progress Report from Bureau of Meteorology Research Centre.................................... 15

Progress Report from CSIRO Atmospheric Research ................................................. 30

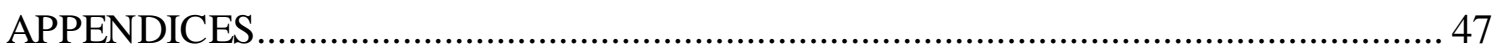

Description of Project

Working paper: LAPS and the Australian Air Quality Forecasting System 
3rd Progress Report

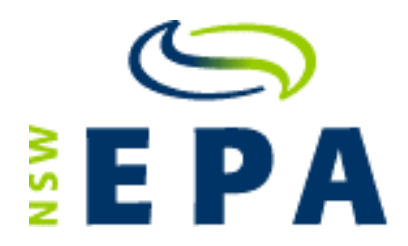




\section{AIR QUALITY FORECASTING FOR AUSTRALIA'S MAJOR CITIES.}

\section{$3^{\text {rd }}$ PROGRESS REPORT}

\section{Introduction}

The Australian Air Quality Forecasting System (AAQFS) is being developed as a collaborative project between CSIRO, Bureau of Meteorology (BoM), Environment Protection Authority of New South Wales (EPANSW) and Environment Protection Authority of Victoria.

EPA NSW' s principal responsibilities are to facilitate the implementation of the forecasting system in Sydney and to provide support to implement the demonstration of the system in time for the 2000 Olympics. The specific deliverables include:

- Providing access to the 1992 emissions inventory with updates for Metropolitan Air Quality Study (MAQS).

- Provision of routine meteorological data for inclusion in the LAPS analyses for NSW.

- Provision of routine ambient air quality data and additional meteorological data for validation of model performance.

- Vertical profiling data from western Sydney by an acoustic sounder funded outside of AAQFS.

- Facilitation for progress of the project, feedback on operational questions and ideas and guidance in the development of forecast presentations.

- Officer time for operational use.

- NSWEPA has commissioned a preliminary study to determine biogenic emissions from trees and grasses. This information will enable validation of the algorithms used in MAQS for biogenic emissions estimates.

\section{Progress Report}

Contracts between NSWEPA/CSIRO and NSWEPA/Vic EPA are currently being finalised. Progress has been made on the majority of the deliverables as outlined below.

\section{Emissions Inventory}

The emission inventory for the Sydney, lower Hunter and Illawarra regions has been provided to the Vic EPA. The inventory covers the area as defined in the MAQS with emission updates for both area and point sources where available.

\section{Meteorological and Data}

Provision of meteorological data on a daily basis is continuing.

\section{Vertical Profiling for Western Sydney}

It is anticipated that vertical profiling for western Sydney will commence sometime in March 2000. A site has been selected and final negotiations are under way for the preparation of the site. 


\section{Air Quality Data}

Provision of 1-hourly ambient data (first level validation) on a daily basis from all stations in the Sydney, lower Hunter and Illawarra regions is also continuing.

Historical air quality data have also been supplied for validation purposes of air quality forecasts on selected event days identified by CSIRO.

\section{Biogenic Emissions}

CSIRO Energy Technology in collaboration with CSIRO Atmospheric Research has been commissioned by NSWEPA to carry out preliminary measurements of biogenic emissions from trees and grasses. We have been advised that, unfortunately, due to weather conditions over the $99 / 00$ summer period, there has been, as yet, no new data collected.

\section{Review of AAQFS web site}

The performance of the web site has been continually reviewed and suggestions have been relayed to CSIRO. Where possible the AAQFS forecasts have been used to inform routine air quality forecasts made by NSWEPA officers on a daily basis.

Days of interest to NSWEPA have also been reviewed.

\section{Facilitation for progress of the Project}

EPANSW has been represented at meetings of the AAQFS Management team.

\section{Conclusion}

- A site has been selected for deployment of a vertical profiler in Western Sydney.

- Provision of ambient air quality data and meteorological data to CSIRO and Bureau of Meteorology is continuing on a routine basis.

- The AAQFS web site is continually reviewed and feedback submitted to CSIRO.

- Where practical, the AAQFS forecast is being incorporated into the routine air quality forecasting carried out by NSWEPA on a daily basis. 
Environment Protection Authority (Victoria)

$3^{\text {rd }}$ Progress Report

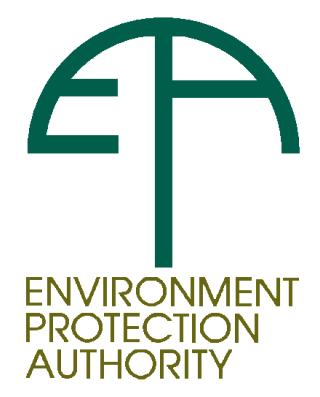




\section{Environment Protection Authority (Victoria)}

\section{3rd PROGRESS REPORT}

\section{Emissions Inventory Component}

\section{Peter Mcallister, Yuk Leung Ng, Sean Walsh and Neil Wong}

\section{Introduction}

This progress report details the state of the tasks for the phase three reporting cycle of the AAQFS project. The key tasks for this phase are the Sydney inventories for the year 2000, the Victorian inventories and the run time system development.

\section{Sydney Inventories}

There are inventory datasets being prepared for four domains:

- greater Sydney region at a grid cell resolution of $0.05^{\circ}$

- Sydney region at a grid cell resolution of $0.01^{\circ}$

- Newcastle region at a grid cell resolution of $0.01^{\circ}$

- Wollongong region at a grid cell resolution of $0.01^{\circ}$

The Sydney inventory $\left(0.05^{\circ}\right)$ has been completed for all emission sources (point, area, motor vehicle and biogenic). There are several data files that will be updated when the data are received from NSWEPA. These data are:

- annual emissions for area and point sources

- spatial data (weekly and monthly/seasonal profiles) for area and point sources

The $0.01^{\circ}$ grid cell domains have been defined. The work was delayed while improved spatial data were sought. However, these spatial data were not obtained and the work to produce the data files is continuing.

The phase three target of 31 December 1999 to complete the Sydney Inventory was not meet due to delays on receiving information from NSWEPA. The Sydney inventories are expected to be complete by 25 February 2000 .

\section{Victorian Inventories}

The Melbourne $0.05^{\circ}$ grid cell domain data have been generated. The $0.01^{\circ}$ grid cell domain has been defined and the data for the four emissions sectors need to be generated. Quality control procedures on the Victorian Inventory have been completed. The Melbourne inventories are expected to be complete by 25 February 2000.

\section{Run Time System Development}

The development of the run time system is behind schedule. The major delay of the run time system was access to the NEC supercomputer. The supercomputer access was obtained in December 1999, which delayed the run time system development by four months. This delay held up the testing and optimisation of the emissions inventory modules on the supercomputer. 


\section{Point Emissions Inventory Module (EIM)}

The point source module was reported to be completed in the second progress report.

However, from further discussions with CSIRO, the EIM was required to be able to process emissions over a 36-hour period, which may span three days. The point EIM has to be modified to allow this functionality. The optimisation of the point EIM on the supercomputer is continuing.

\section{Area EIM}

The area-based module is almost complete. The same modification as the point EIM was required for the area EIM to process emissions over a three day period. Development of the meteorologically dependent emissions component has been finished. Optimisation of areabased EIM on the supercomputer is underway.

\section{Motor Vehicle EIM}

The motor vehicle EIM is continuing. Work completed for the motor vehicle EIM includes:

- VKT-based EIM has been written for the pollutants CO, NOx and VOC

- the completed parts of the VKT-based EIM has been tested on the supercomputer.

Work to be completed for the motor vehicle EIM includes:

- finish writing code for the VKT based EIM for other pollutants

- incorporated power based emissions

- testing and optimisation of the EIM on the supercomputer.

\section{Biogenic EIM}

With the delays in the run time system, the biogenic EIM was given the lowest priority of the four EIM. The outstanding work includes producing the biogenics EIM and testing/optimisation on the supercomputer.

\section{Meteorological Data}

1 -hourly ambient data (first level validation) are being provided daily to the Bureau of Meteorology from all stations within the Port Phillip Control Region. The data are being used to validate LAPS modelling.

\section{Air Quality Data}

EPA Victoria is also providing daily CSIRO with first level validated 1-hourly ambient data from all stations within the Melbourne Basin. The data are being used for preliminary validation of air quality forecasts. EPA is investigating the feasibility of FTP for data transfer rather than email.

\section{Vertical Profiling for Melbourne}

The acoustic sounder is to be sited at the Werribee Treatment Plant owned by Melbourne Water. The contract between EPA and Melbourne Water has not been finalised but is expected soon. Once the contract has been signed off, the expected time for the acoustic sounder to be in operation is six weeks. 


\section{Status of Agreements}

The CSIRO-EPA agreement is currently with the EPA Solicitor, and feedback is expected in the next two weeks. A draft MoU from Bureau of Meteorology in relation to continued use of the system has not yet been received.

EPA is currently considering the CSIRO request to make access to the webpage containing the data available more widely. A response is anticipated in the next few weeks.

\section{Conclusion}

The tasks under the phase three reporting cycle are continuing. The current timetable for completion of tasks is presented in Table 1.

Table 1. Timetable for the Phase Three Tasks

\begin{tabular}{|l|l|}
\hline Task & Completion Date \\
\hline Sydney Inventories & $25 / 2 / 00$ \\
\hline & \\
\hline Victorian Inventories & $25 / 2 / 00$ \\
\hline & \\
\hline Point Based EIM & $10 / 2 / 00$ \\
\hline Area Based EIM & $18 / 2 / 00$ \\
\hline Motor Vehicle EIM & $1 / 3 / 00$ \\
\hline Biogenic EIM & $5 / 4 / 00$ \\
\hline
\end{tabular}


$3^{\text {rd }}$ Progress Report

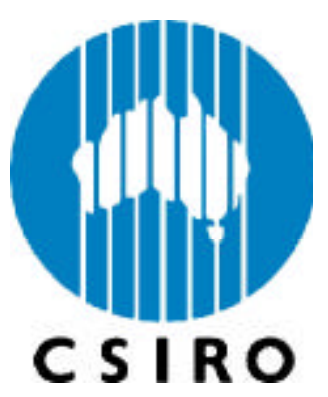




\section{CSIRO Energy Technology}

\section{$3^{\text {rd }}$ Progress Report}

\section{Merched Azzi, John Carras, Martin Cope and David Williams}

\section{GRS developments}

The Generic Reaction Set (GRS) mechanism is being used to model chemical transformation processes for the Australian Air Quality Forecasting System (AAQFS). The GRS mechanism has been selected for this task because of its ability to reproduce the results of larger mechanisms over a range of important urban conditions, but at a fraction of the computational cost.

During the reporting period the GRS mechanism

- has been extended to provide an improved simulation of rural/background photochemical production processes (such as $\mathrm{O}_{3}$ production from methane and other background species under conditions of low $\mathrm{NO}_{\mathrm{x}}$ )

- is being modified to accommodate an explicit treatment of the key radical species such as the hydroxyl radical and various peroxy radicals. (This will also enable an improved treatment of secondary particle formation to be developed).

Detailed testing of the GRS-V2 performance compared to a CBIV simulation and selected smog chamber data is currently being carried out.

\section{Power based motor vehicle modelling}

A primary road network for Sydney has been developed in a form that can provide input for the CSIRO power based model for motor vehicle emissions. Progress to date is as follows;

- A 2D GIS data set of the Sydney major road network was broken up into sub-links of approximately $10-\mathrm{m}$ length giving a total of 355,530 links. The se data were transformed into three dimensions using a terrain map interpolated to provide altitude data at the appropriate scale.

- For each major road the location of each intersection is being determined.

- Traffic volumes are being assigned to each link from a primary data set obtained from the RTA. The data consist of 15-minute averages for each hour of the day.

- A generic model to allow emissions from intersections to be calculated has been completed and is being tested.

- The CSIRO power based emission model has been reformulated to receive the GIS formatted road network.

- The output from the power based emissions modelling is being developed so as to be compatible with the inventory data being provided by EPAV.

The approach described above has been applied systematically to Epping Road and is now being applied to other major roads in the Sydney region. 


\section{Bureau of Meteorology Research Centre}

$3^{\text {rd }}$ Progress Report

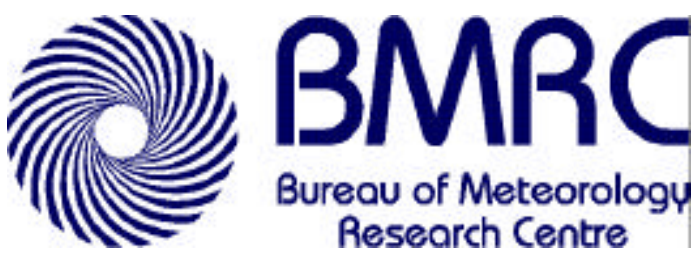




\title{
Third AAQFS Progress Report from the Bureau of Meteorology: Model Validation
}

\author{
G. D. Hess, K. Tory, J. McBride and G. A. Mills
}

\section{Introduction}

A limited area meteorological model with 29 vertical levels and $5-\mathrm{km}$ horizontal resolution is used to forecast the winds, temperature and humidity structure that will occur in the next 36 hours. Two separate domains are used; they essentially cover the states of Victoria and New South Wales, respectively. The forecasts are produced twice daily, and the information obtained from these forecasts is used as input for the photochemical model to calculate the transport and dispersion of chemical species.

In the original pilot scheme the meteorological model had 19 vertical levels and $5-\mathrm{km}$ horizontal resolution. This model has been substantially upgraded. The vertical resolution has been increased to 29 vertical levels. The model physics has also been improved. Instead of a simple hydrological balance called a 'bucket model', the multiple level Viterbo-Beljaars prognostic diffusive hydrological scheme is employed. Previously the surface fluxes were computed indirectly using the Louis algebraic scheme and the vertical diffusion was computed using the Louis first-order closure scheme. Now the surface fluxes are obtained directly from the Monin-Obukhov profile functions by iteration and the vertical diffusion in convective conditions is computed by the Troen-Mahrt large eddy parameterisation of the vertical diffusivity. The topography resolution was 10 minute resolution; it has now been increased to 30-second resolution. The sea surface temperature input data were at 10 minute spatial resolution obtained weekly; they are now at 0.250 degree spatial resolution obtained daily. The effects of vegetation have been added. The parameterisation of the land-surface interaction has also been improved by introducing a momentum roughness length due to the topography, in addition to skin friction, and a separate roughness length for heat and moisture.

\section{Status}

The emphasis of this report is on model validation. Since our last report, we have been developing a number of validation techniques and procedures to test the meteorological model' s performance. These can be divided into two groups: (i) daily validations which sum up the daily performance of the model in a single value, i. e. root-meansquare error; and (ii) event validation, which focusses on the meteorological detail over the spatial and temporal domains during the event. The "daily" validation process identifies problem events, which can be examined in more detail with the "event" validation procedure. During the last ozone season there were two events that breached the hourly average ozone standard of $100 \mathrm{ppb}$ - one in Melbourne on 10 December 1998 and one in Sydney on 13 December 1998. We have carried out detailed case studies of both of these events. The analysis of the Melbourne event is given in the attached report, LAPS and the Australian Air Quality Forecasting System. In the present report we will examine the Sydney event.

The main body of the report is divided into four sections. The first describes the meteorology of the Sydney case, which is actually a multi-day event. To do this we use the surface wind "event" validation technique for illustration. The second and third 
sections describe the surface temperature and lower atmosphere wind and temperature "event" validation techniques, which demonstrate encouraging model performance during the multi-day event. The fourth section introduces two of the "daily" validation procedures.

\section{Multi-day Sydney event:}

The Sydney case was a multi-day event of higher than background ozone concentrations. The region was dominated by a high pressure cell to the east of Sydney, which created general subsidence and limited the height of the mixing (see Fig. 1). By 1100 UTC 12 December 1998 the synoptic pattern was beginning to change. Although the high pressure cell remained in the Tasman Sea, a trough formed east of Tasmania and extended up the east coast of Victoria. This trough was associated with a cold front known as a "Southerly Buster", and it produced a southerly wind surge up the coast. It was a transient feature; by 1100 UTC 13 December 1998 it had disappeared. In Fig. 2 we show the wind pattern corresponding to the first two of these days. There was very little change in the wind direction and speed over $11-12$ December 1998. Northerly nighttime flow turned to northeasterly flow during the daytime.

The flow was uniform in direction all along the coast. The red wind barbs indicate observations and the blue barbs are the model predictions. It is seen that in general there is good agreement between the predictions and the observations.

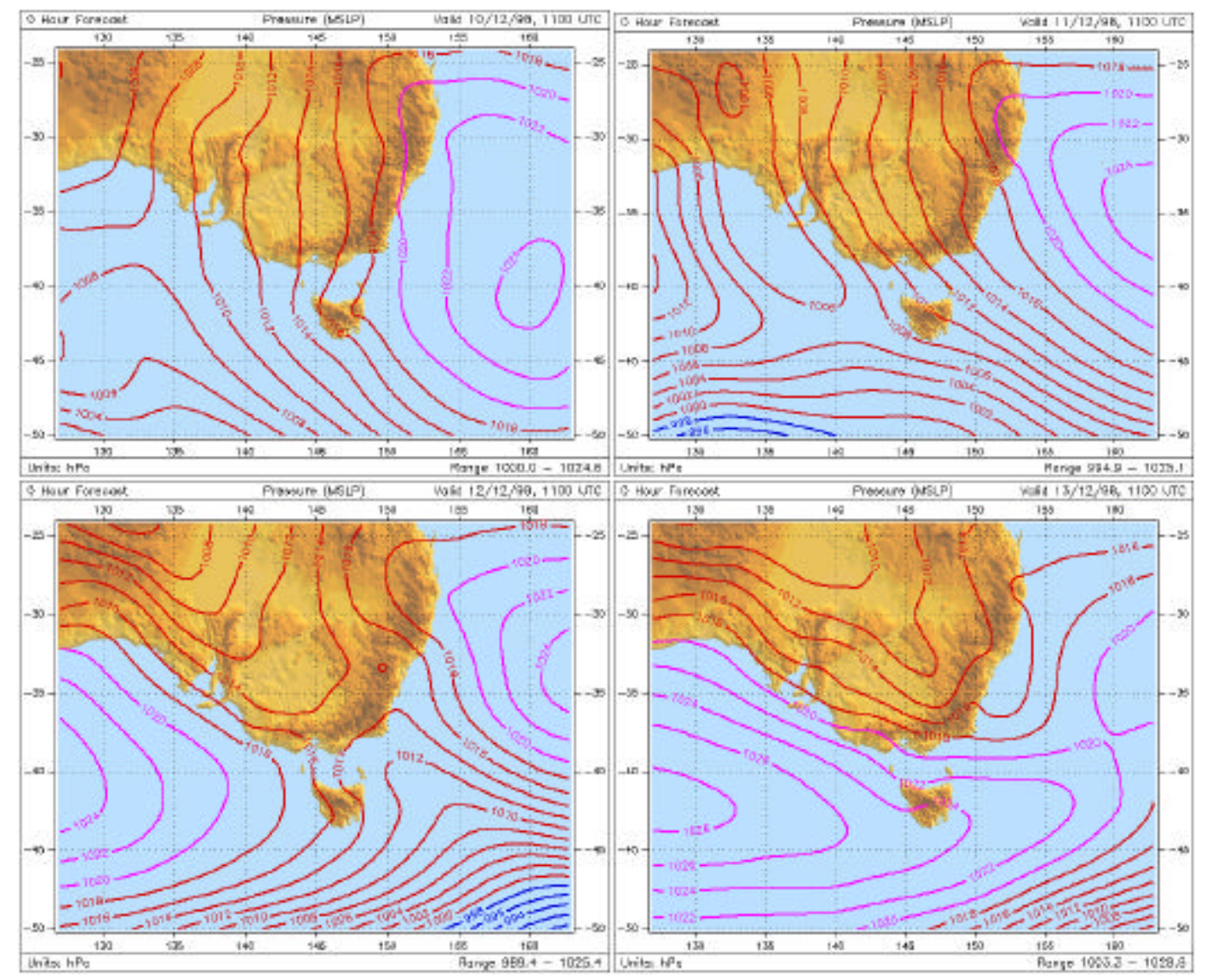

Figure 1. Synoptic mean sea-level pressure pattem at 1100 UTC 10 December 1998 - 1100 UTC 13 December 1998. 

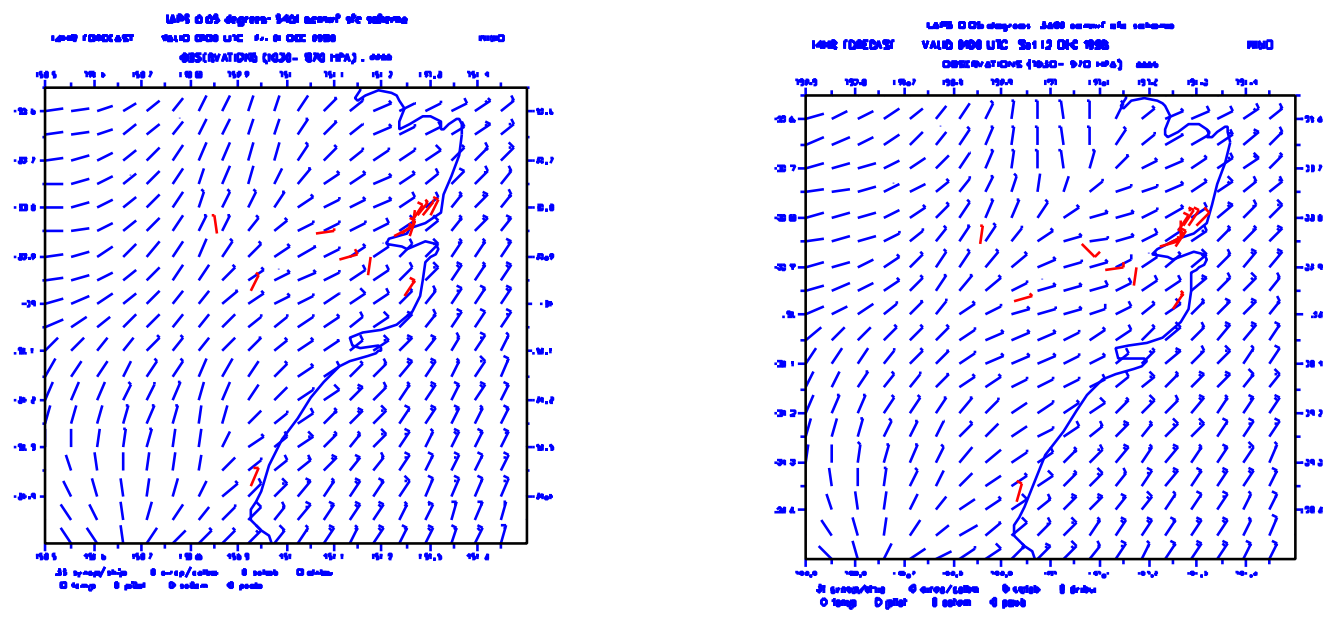

Figure 2. (a) The validated wind field for 0100 UTC 11 December 1998 (12 noon EDT); (b) the same as (a), except for 0100 UTC 12 December 1998 . Full wind barbs = 10 knots; half barbs = 5 knots; no barb = 2 knots; 1 knot $=0.5 \mathrm{~m} / \mathrm{s}$.

The meteorology for 13 December 1998 was more complex. In Fig. 3 we set the scene by showing a map with place names of locations described below. O vernight a weak westerly drainage flow carried the previous day' s ozone plume eastward towards metropolitan Sydney. The westerly flow carried ozone precursors further eastward out over the Tasman Sea. A trough line (an imaginary line on the map around which the wind s rotate in a clockwise direction) from the southwest of the domain shown in Fig. 4 moved northward and by 2100 UTC 12 December 1998 had formed a mesoscale low (a point around which the winds rotate in a clockwise direction) south of Botany Bay, bringing onshore flow at Wollongong (Fig. 4a). This low moved northward to Botany Bay in the next hour and a new mesoscale low formed north of Broken Bay. By 2300 UTC (Fig. 4b) the mesoscale low north of Broken Bay had intensified, bringing onshore flow along the whole coast between Broken Bay and Shellharbour and bringing the precursors back over land. This mesoscale low then slowly drifted to the northeast and by 0100 UTC 13 December 1998 (Fig. 4c) the flow along the coast had turned more southeasterly. By 0300 UTC (Fig. 4d) the continued drift of the low meant that winds along the coast had now turned to southerlies. After this (Figs. 5a and 5b) the low has moved east of our domain and the flow over the sea is southerly, but over the land becomes southeasterly. This flow transported the ozone plume northward and then to the northwest. As before in general the wind predictions are good, although at some hours there is a slight error in the location of the mesoscale low and the timing of its drift.

In order to obtain an overview we show the wind field for the full N SW domain in Fig. 6 for every $10^{\text {th }}$ grid point for 0500 UTC 13 December 1998 . The southerly wind surge ("Southerly Buster") is clearly visible and is seen to be confined to the region along the coast. This type of wind surge occurs in the Sydney Basin during the warm months. 


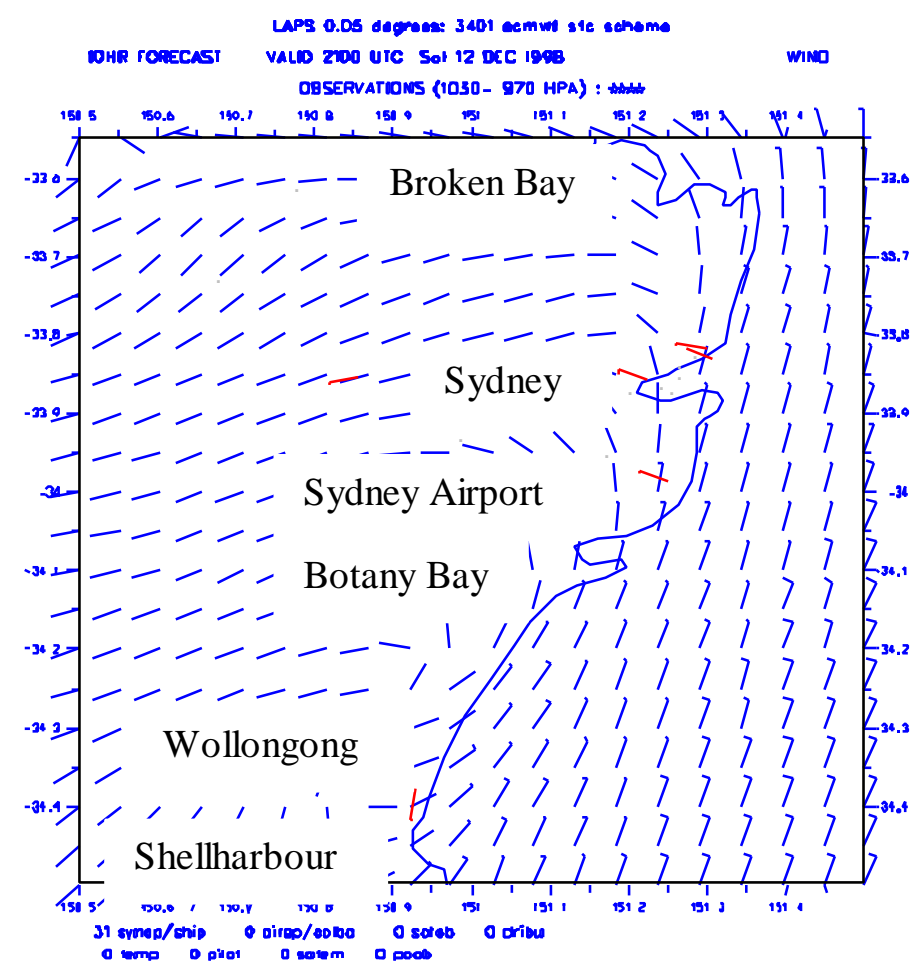

\section{Figure 3. Approximate location of places cited in the text (note these are coastal locations; their position has been displaced slightly to the west in order to preserve the coastline.)}

\section{Near-surface temperature validation}

In addition to the validated wind fields we have developed other methods to validate the model predictions. In Fig. 7 we present a comparison for the near-surface temperature from observations (AMDAR based on measurements from commercial aircraft; in this comparison the aircraft are on the runway) and the LAPS model first level data (interpolated to the height of the aircraft; approximately $10 \mathrm{~m}$ height). The model captures the diurnal temperature cycle well. Note the spike at 1100 UTC 12 December 1998 in the LAPS curve. The plot is a composite of three model runs. The spike is due to an error in initialising the temperature for the last run. It is not considered to be a serious error. The reason is in the first few hours after starting a run, the model undergoes a period of adjustment known as "spin up", at the end of which the flow comes into balance with boundary forcing conditions. After the model has spun up (in this case by early morning) the predicted and the observed temperatures again come into agreement. Also note that there are no flights overnight and the AMDAR data are interpolated in this period. Aside from the initialisation error the agreement between the model and observations is quite encouraging. 

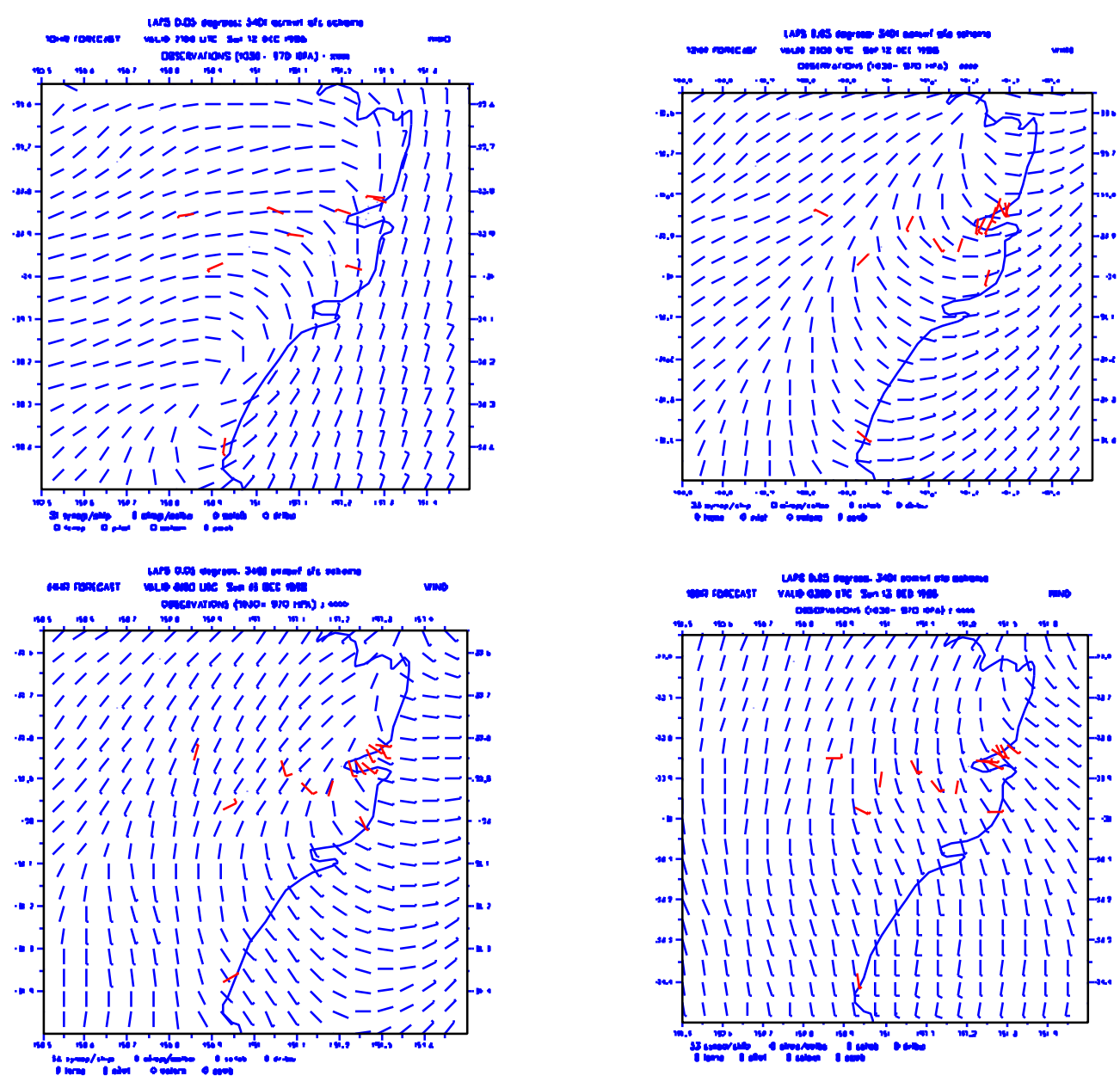

Figure 4. (a ) Validated wind field for 2100 UTC 12 December 1998; (b) for 2300 UTC 12 December 1998; (c) for 0100 UTC 13 December 1998; (d) for 0300 UTC 13 December 1998.
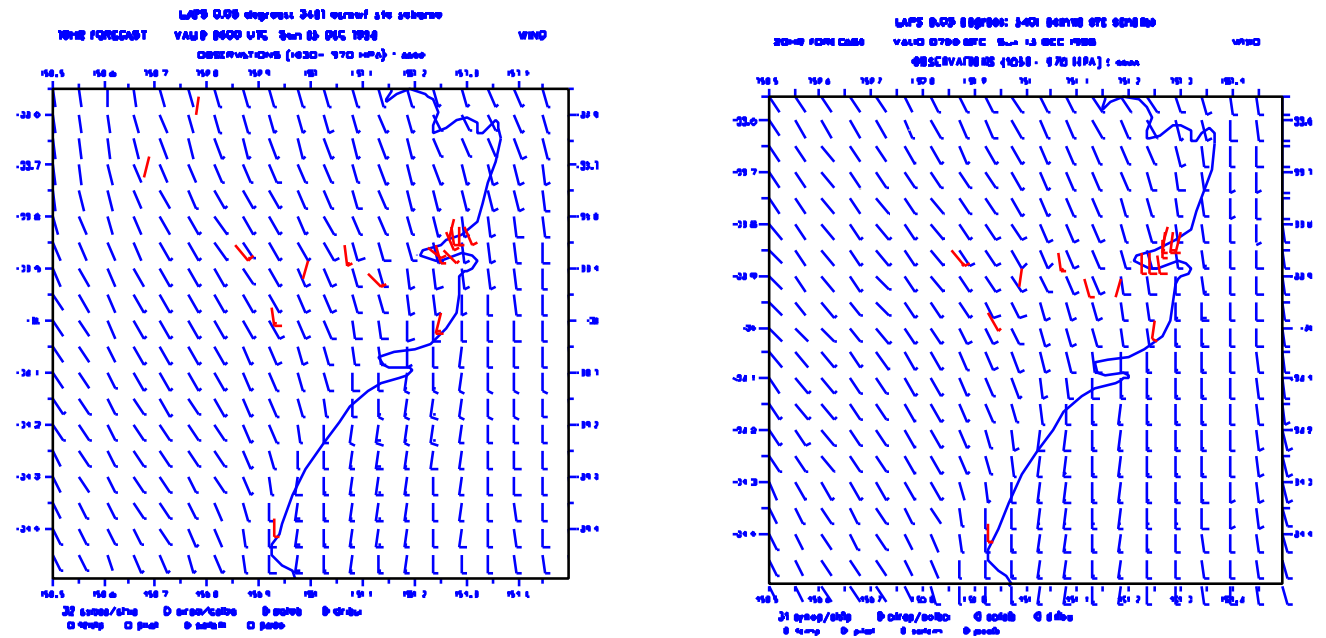

Figure 5. (a) Validated wind field for 0500 UTC 13 December 1998 ; (b) for 0700 UTC 13 December 1998. 


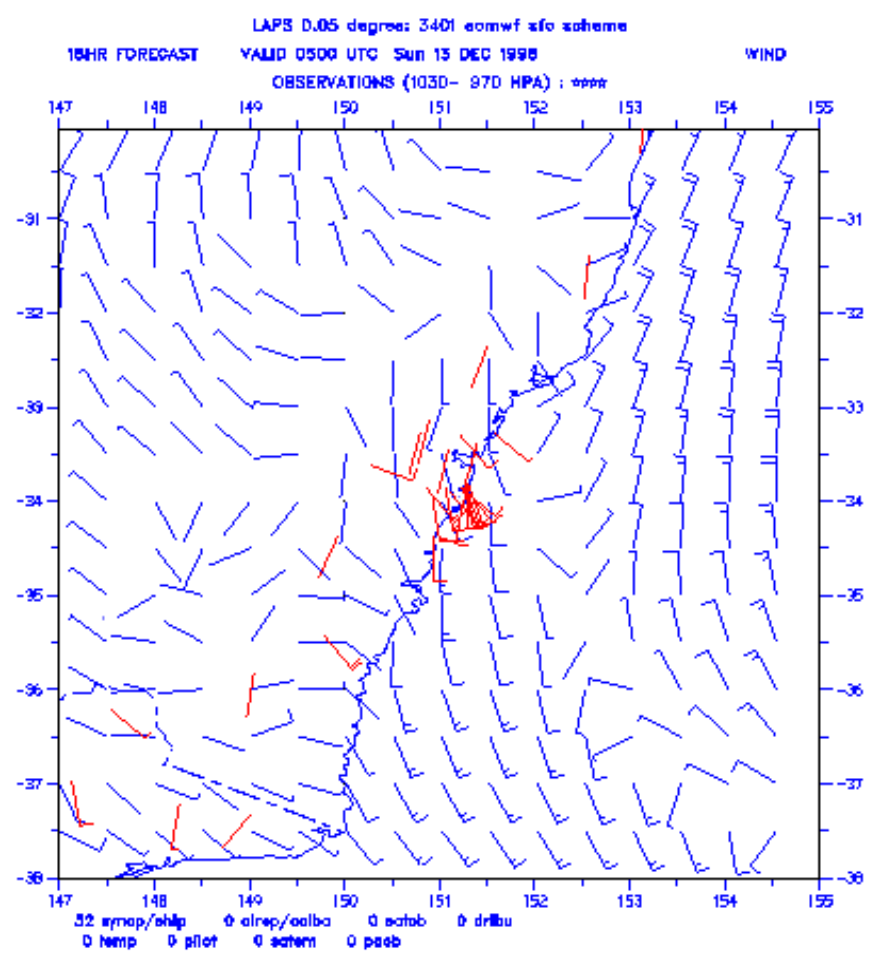

\section{Figure 6. Validated wind field for 0500 UTC 13 December 1998 for the whole domain. Every 10th grid point is shown. Note the southerly wind surge up the coast, the "Southerly Buster".}

Figure 8 presents a comparison of the observed screen temperature and screen dew point temperature (based on the METAR/SYNOP network of automatic weather station measurements) and the LAPS model predictions at 2-m height. Notice the increase in the amplitude of the diurnal cycle compared to Fig. 7, because the data are measured at a point nearer the ground $(2 \mathrm{~m}$ compared to $10 \mathrm{~m}$ ). The agreement is very good almost everywhere. Again there are spikes in the computed results due to errors in initialisation of the LAPS runs. Also the difference in the temperature-dew points indicates that the LAPS model has a slight bias towards being too moist at this coastal location. Improvement in the initialisation of soil moisture may help reduce this bias.

This type of presentation highlights weaknesses in the present method of model initialisation. Model initialisation at $5-\mathrm{km}$ resolution is a whole new area of research at the frontier of scientific knowledge. It is an area that we are devoting considerable effort to develop.

\section{Lower atmosphere validation}

Another method of valid ation consists of constructing time-height diagrams of wind and potential temperature and determining the boundary-layer height and the ventilation (the product of boundary-layer height and the average wind speed within the boundarylayer). Figure 9 shows the AMDAR data collected by aircraft taking off and landing at Sydney Airport, starting at 1100 UTC 10 December 1998. The yellow curve marks the estimated boundary-layer height. Above the boundary-layer the flow is stably stratified 
and there is little mixing to dilute pollutants reaching these heights. The low value of the bound ary-layer height for the full period indicates that the vertical mixing of pollutant concentrations was restricted during the daytime as well as at nighttime and concentrations could be expected to be high. The equivalent plot based on the LAPS model is shown in Fig. 10. Data are extracted from the model output following the same three-dimensional path at the aircraft. Figures 11-14 show the same type of comparison for the other two days of the event. The comparisons show good agreement between the predicted and observed values.

\section{Daily validation}

Lastly we present some time series that give quantitative measures of model performance for the entire domain over time for wind and temperature and near the airports for ventilation. The indices are a vector root-mean-square (RMS) error for the 10 - $\mathrm{m}$ wind, a RMS error calculated in a similar way to include both screen temperature and dew point temperature, RMS errors for wind and temperature at all heights (from AMDAR/LAPS comparisons), and a comparison of the observed and predicted mean ventilation. These are shown in Figs. 15 - 20, respectively. Note that with increasing height the wind strengthens and wind errors increase. Also note that the difference in the magnitude of the mean ventilation for Melbourne and Sydney reflects the location of the airports. Melbourne Airport is located inland where the diurnal temperature cycle is pronounced; Sydney Airport is located on the coast where the diurnal temperature cycle is much smaller.

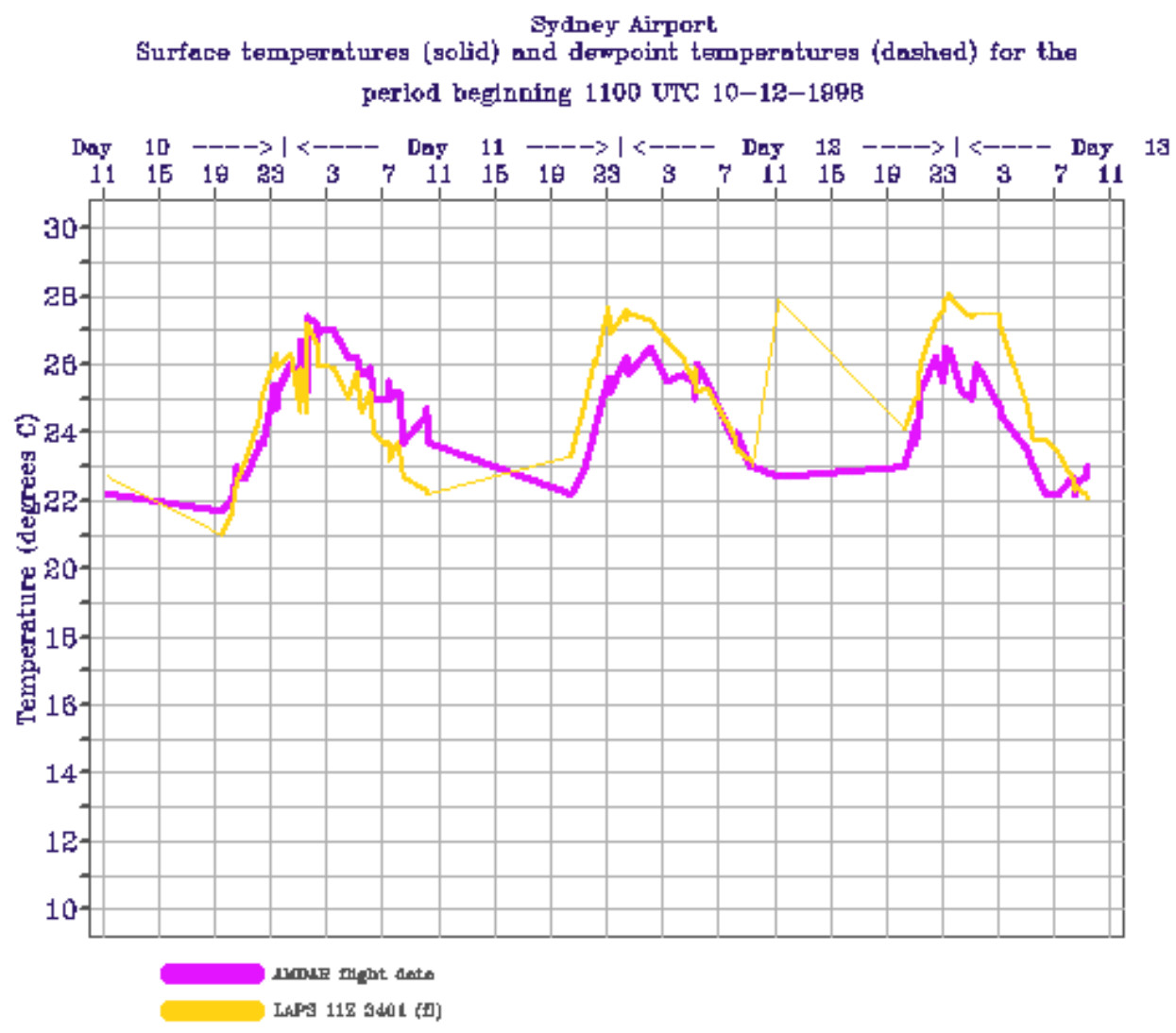

Figure 7. Comparison of observed near-surface temperature from AMDAR and the predicted temperature from LAPS for 1100 UTC 10 December 1998 to 1100 UTC 13 December 1998 at Sydney Airport. 


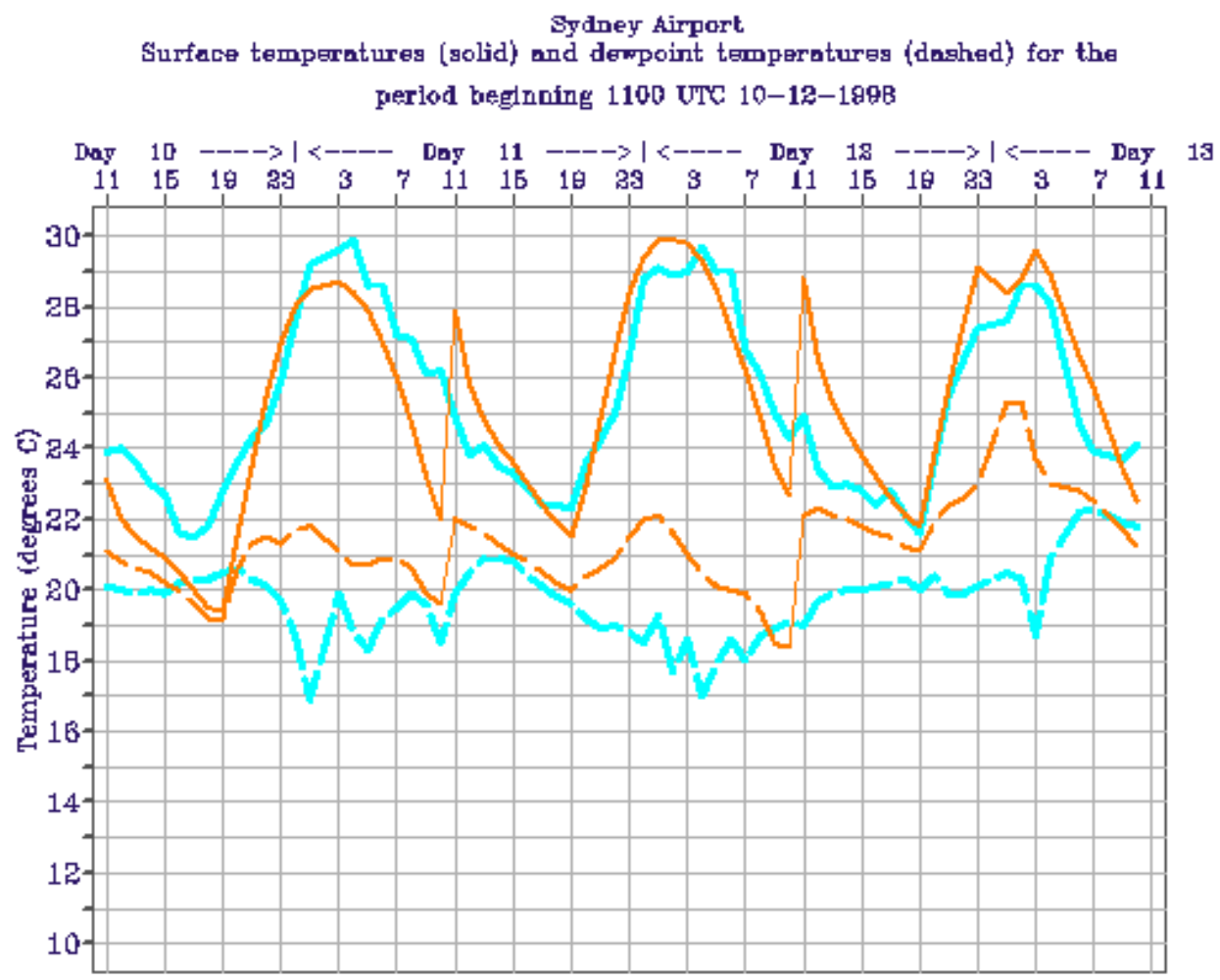

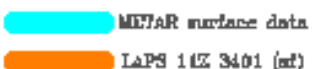

Figure 8. Comparison of observations (METAR/SYNOP) and LAPS predictions for screen temperature (solid lines) and screen dew point temperature (broken lines) for 1100 UTC 10 December 1998 to 1100 UTC 13 December 1998 at Sydney Airport.

The results show that on the whole the model is performing well in trials for both NSW and Victoria. Occasions indicating a marked variation in performance in these Figures alert us to situations that need closer examination.

\section{Conclusions}

We have developed a range of validation methods to examine the performance of the meteorological model. These methods indicate that overall the model performs well. However, there are occasions when the model performance needs improvement. The tools that we have developed help us to identify those occasions. Several of the weaknesses in performance have been linked to the model initialisation, and we are working to improve our methodology in this area. One idea that we will test is to assimilate data in the initialisation process so that the model is adjusted to the initial conditions at the beginning of the run. Also additional vertical resolution in the boundary-layer of the model would be helpful. Lastly, further "daily" and "event" validation techniques are being developed. 
Sydney flights (AMDAR data), from 11 UTC (10-12-9B)

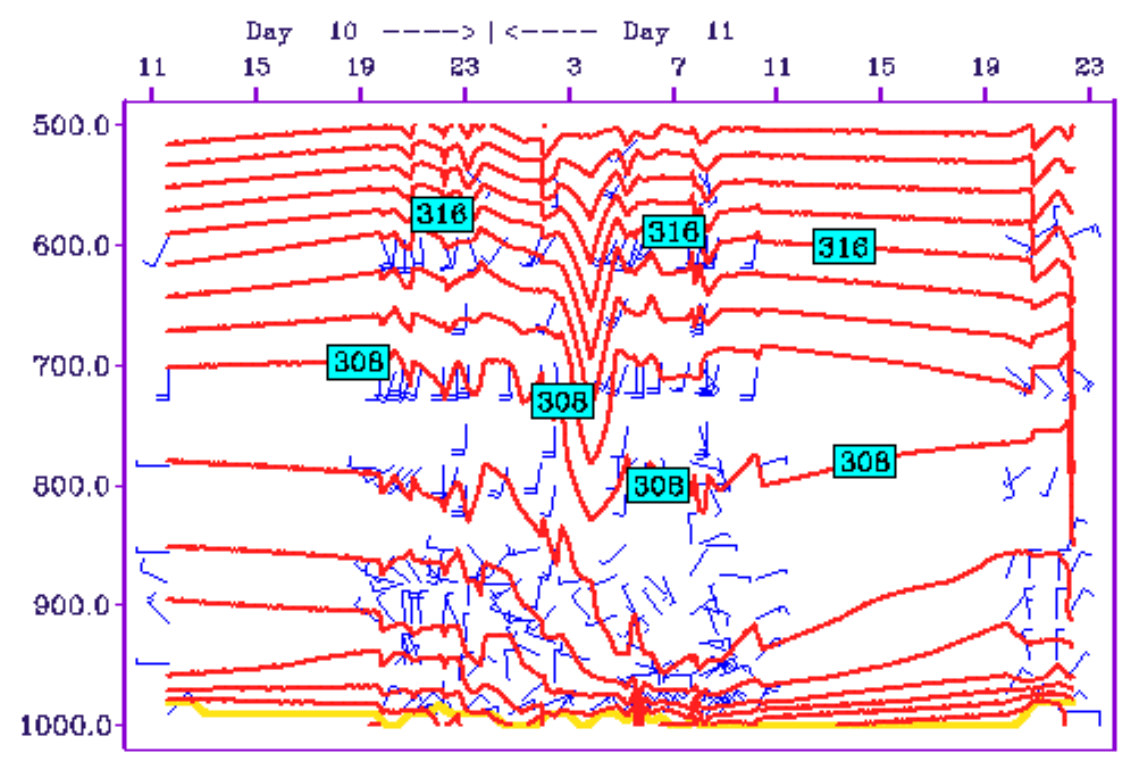

Figure 9. Time-height cross section of potential temperature and winds, based on AMDAR data, starting at 1100 UTC 10 December 1998. The temperature contour interval is $2 \mathrm{~K}$. For the wind barbs, flag $=40 \mathrm{knots}$, full barb $=8 \mathrm{knots}$, and half barb $=4$ knots. The speed in $\mathrm{m} / \mathrm{s}$ is half these values. The yellow curve indicates the boundary-layer height.

Sydney flights ( LAPS deta), from 11 UTC (10-12-98)

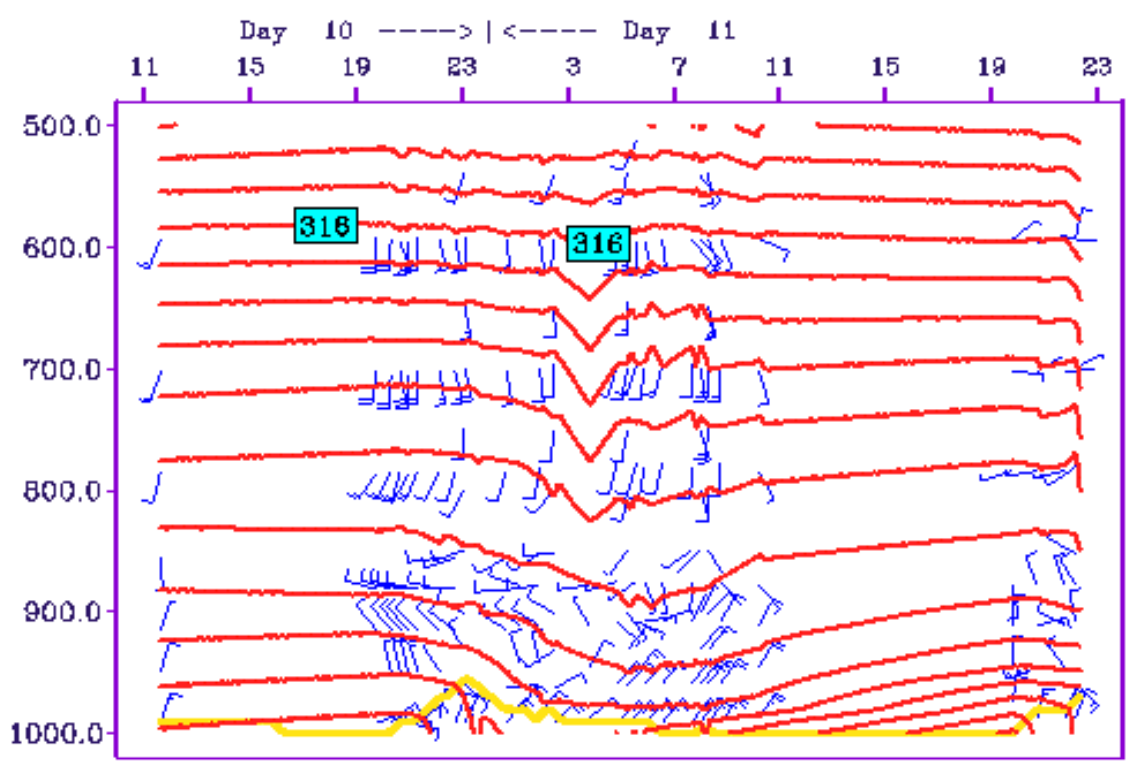

Figure 10. Time-height cross section of potential temperature and winds, based on LAPS data, starting at 1100 UTC 10 December 1998. The temperature contour interval is $2 \mathrm{~K}$. For the wind barbs, flag $=40 \mathrm{knots}$, full barb $=8 \mathrm{knots}$, and half barb $=4$ knots. The speed in $\mathrm{m} / \mathrm{s}$ is half these values. The yellow curve indicates the boundary-layer height. 
Sydney flights (AMDAR data), trom 11 UTC (11-12-98)

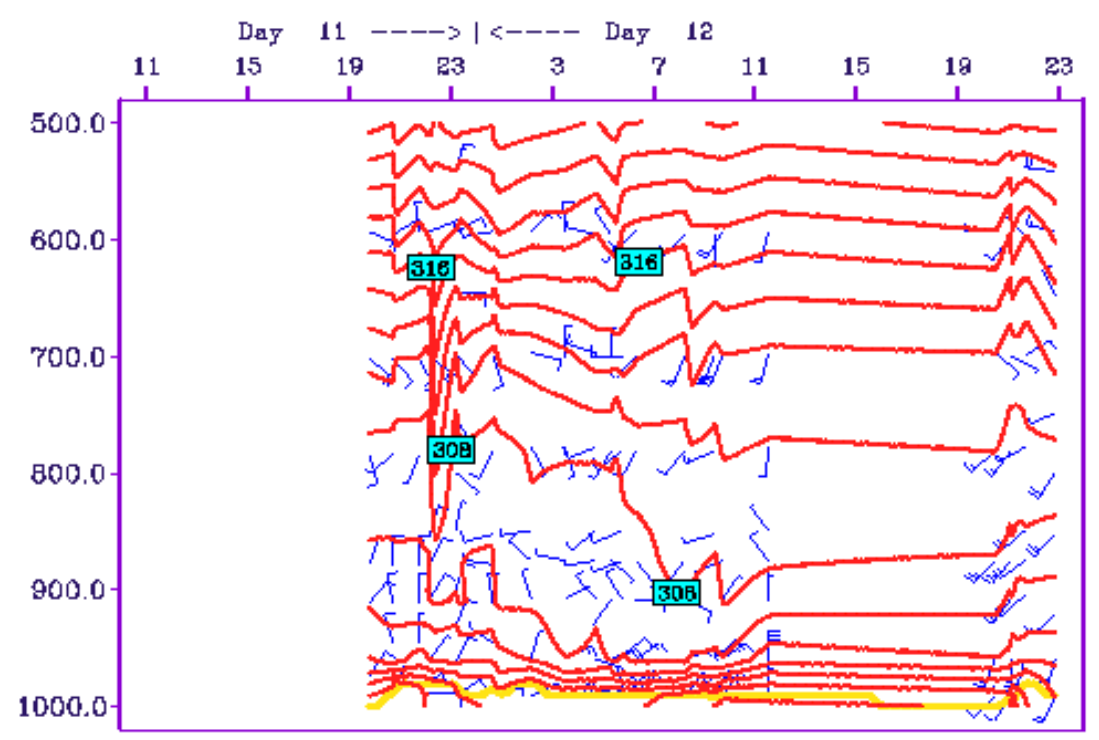

Figure 11. Time-height cross section of potential temperature and winds, based on AMDAR data, starting at 1100 UTC 11 December 1998. The temperature contour interval is $2 \mathrm{~K}$. For the wind barbs, flag $=40 \mathrm{knots}$, full barb $=8$ knots, and half barb $=4$ knots. The speed in $\mathrm{m} / \mathrm{s}$ is half these values. The yellow curve indicates the boundary-layer height.

Sỵdney flights ( LAPS deta), from 11 UTC (10-12-98)

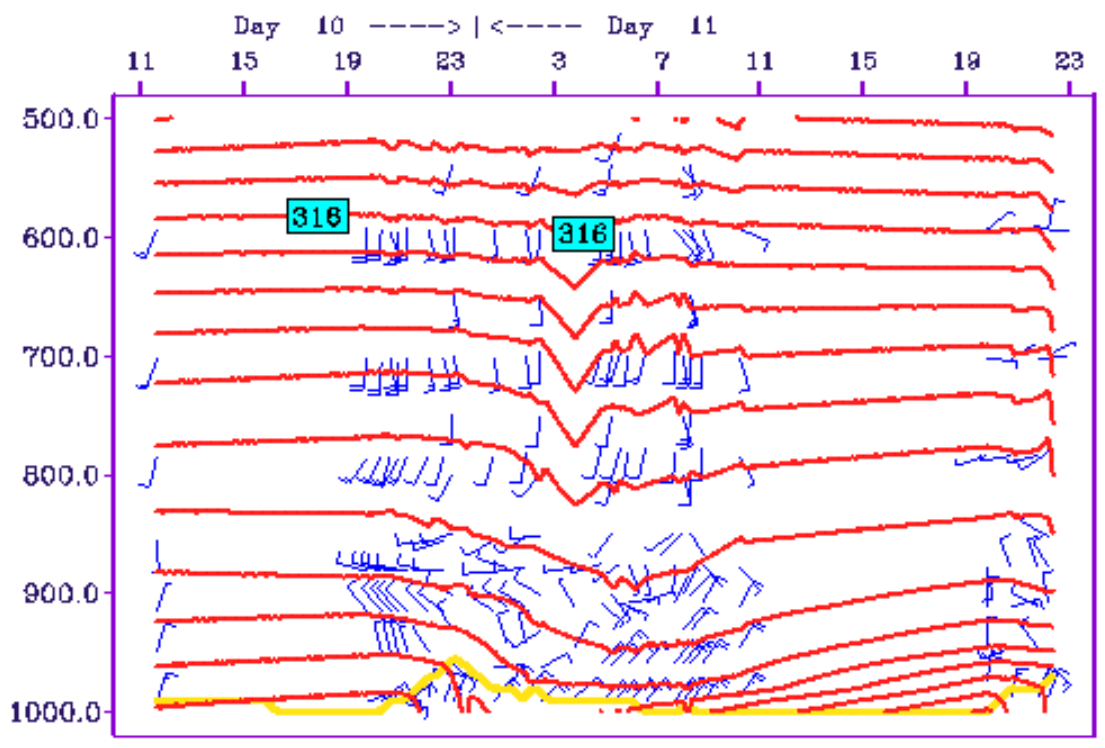

Figure 12. Time-height cross section of potential temperature and winds, based on LAPS data, starting at 1100 UTC 11 December 1998. The temperature contour interval is $2 \mathrm{~K}$. For the wind barbs, flag = $40 \mathrm{knots,}$, full barb $=8$ knots, and half barb $=4$ knots. The speed in $\mathrm{m} / \mathrm{s}$ is half these values. The yellow curve indicates the boundary-layer height. 
Sydney flights (AMDAR deta), from 11 UTC (12-12-98)

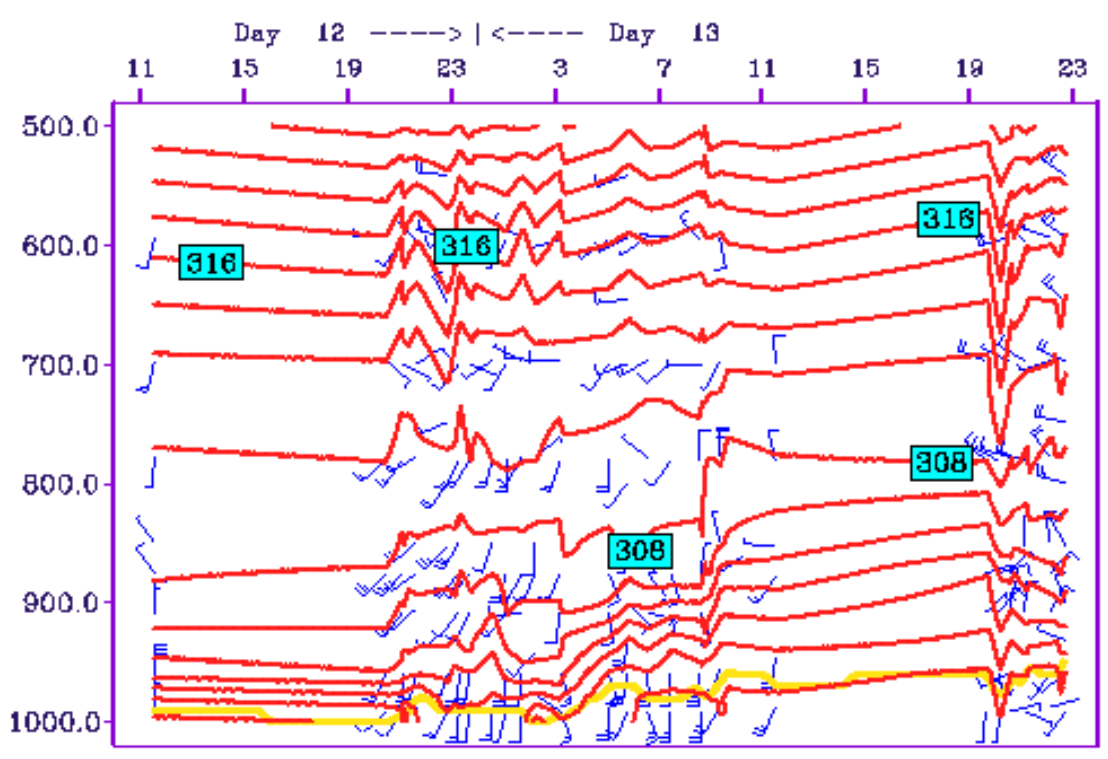

Figure 13. Time-height cross section of potential temperature and winds, based on AMDAR data, starting at 1100 UTC 10 December 1998. The temperature contour interval is $2 \mathrm{~K}$. For the wind barbs, flag = $40 \mathrm{knots}$, full barb $=8$ knots, and half barb $=4$ knots. The speed in $\mathrm{m} / \mathrm{s}$ is half these values. The yellow curve indicates the boundary-layer height.

Sydney flights ( LAPS data), from 11 UTC (12-12-98)

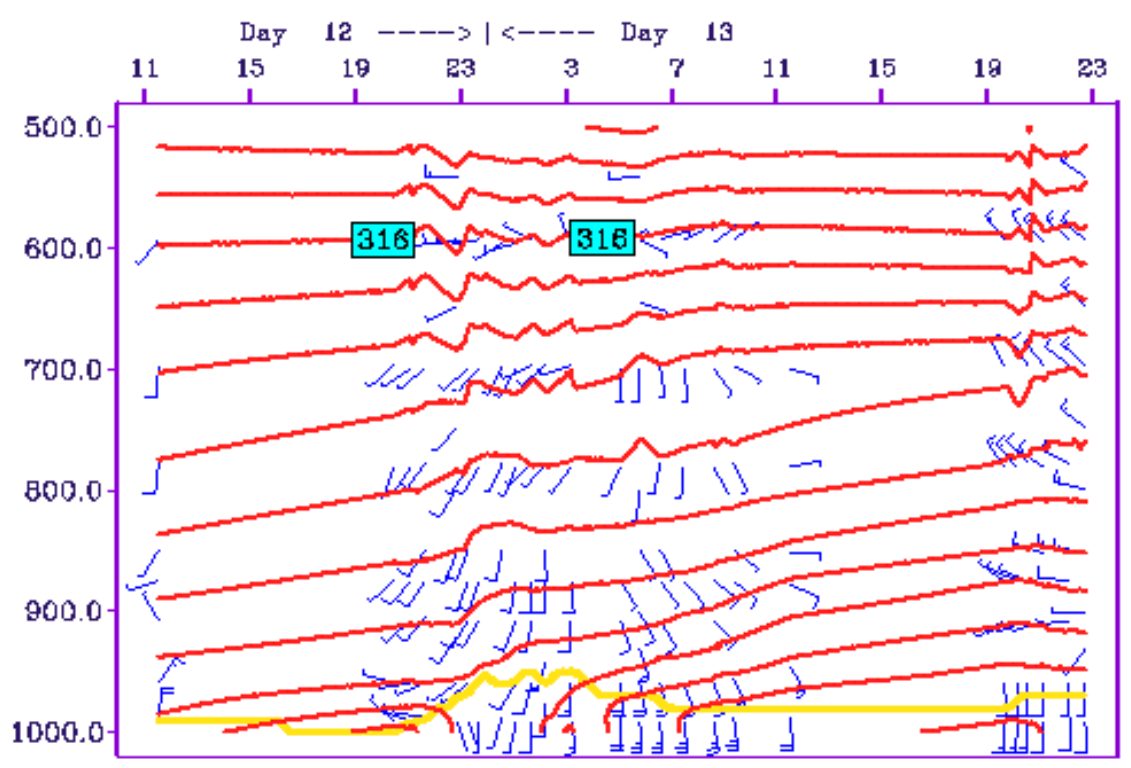

Figure 14. Time-height cross section of potential temperature and winds, based on AMDAR data, starting at 1100 UTC 10 December 1998. The temperature contour interval is $2 \mathrm{~K}$. For the wind barbs, flag $=40 \mathrm{knots}$, full barb $=8$ knots, and half barb $=4$ knots. The speed in $\mathrm{m} / \mathrm{s}$ is half these values. The yellow curve indicates the boundary-layer height. 


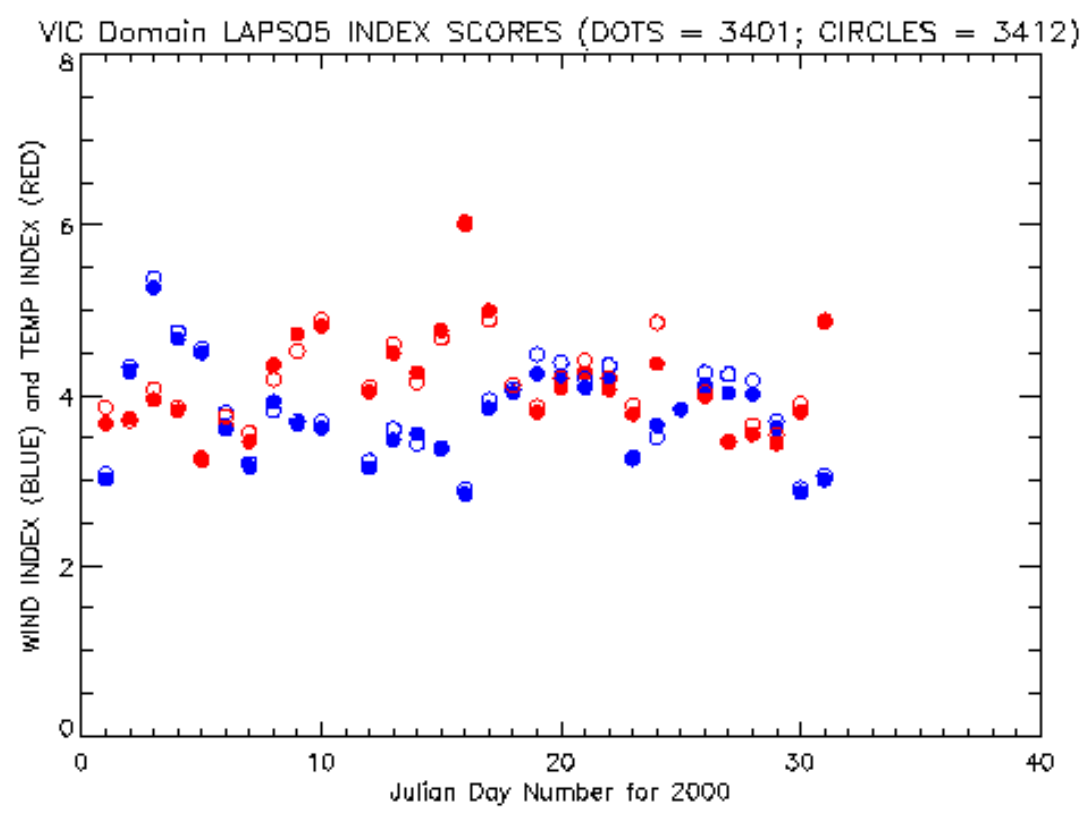

Figure 15. Times series of the near-surface wind and temperature indices for the Victorian domain. The wind index is the vector wind RMS error for the wind at $10 \mathrm{~m}$ height; the temperature index is the RMS error for screen temperature and screen dew point temperature. 3401 is the standard version of LAPS; 3412 is an experimental version with increased complexity in calculating the soil hydrology.

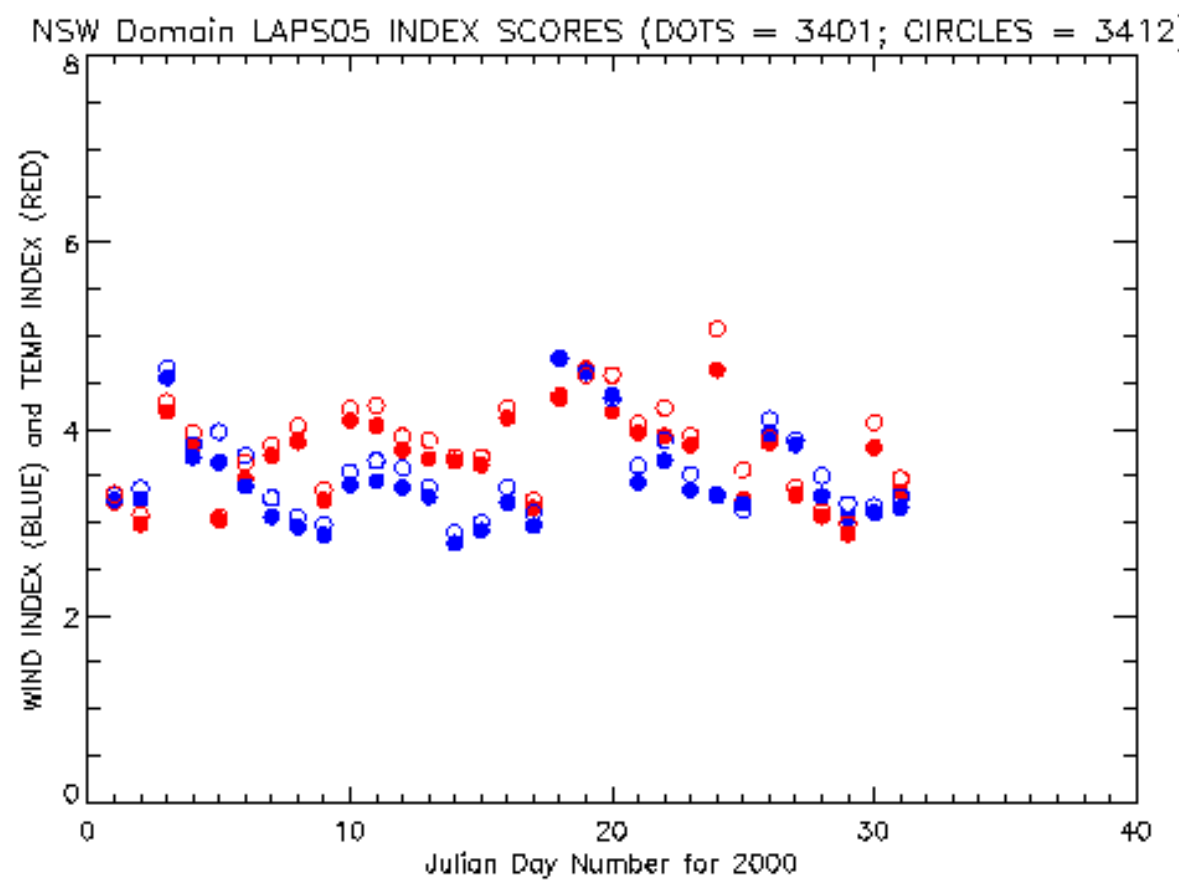

Figure 16. Times series of near-surface wind and temperature indices for the NSW domain. The wind index is the vector wind RMS error for the wind at $10 \mathrm{~m}$ height; the temperature index is the RMS error for screen temperature and screen dew point temperature. 3401 is the standard version of LAPS; 3412 is an experimental version with increased complexity in calculating the soil hydrology. 


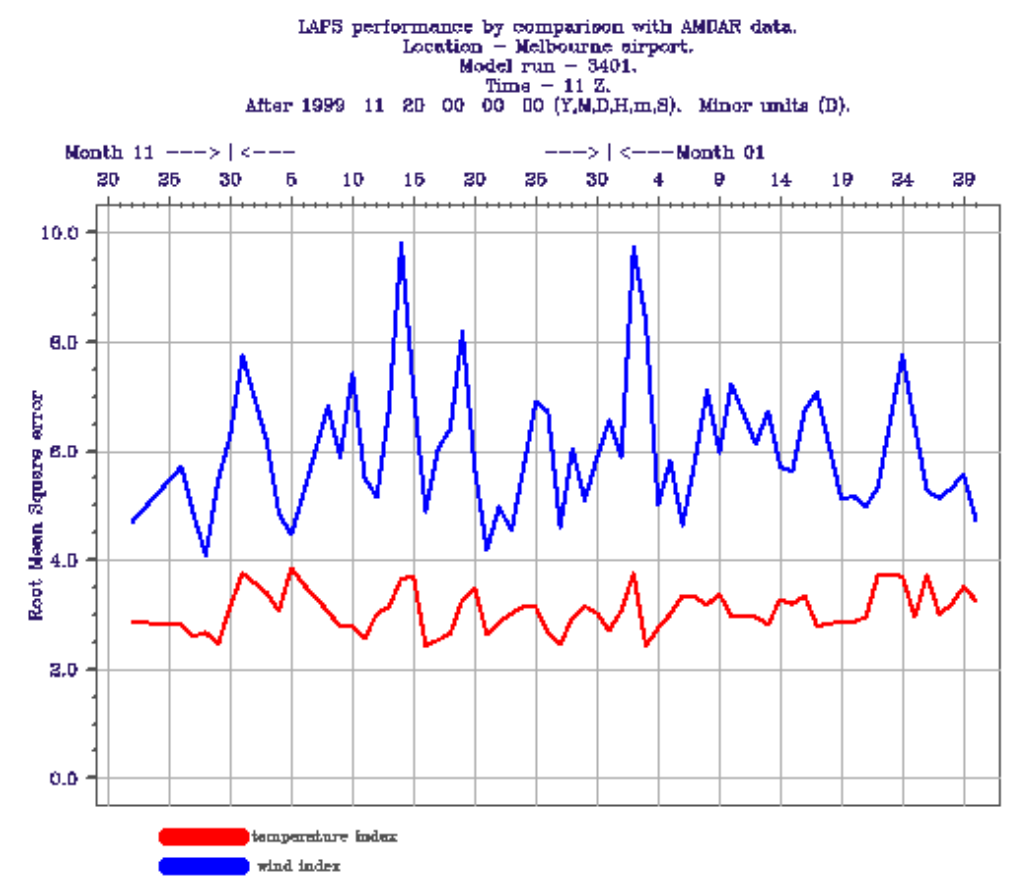

Figure 17. Time series of wind and temperature indices for the Victorian domain. The wind index is the RMS vector wind error; the temperature index is the RMS temperature error. The calculations are based on AMDAR/LAPS comparison for flights to and from Melbourne Airport and include all heights.

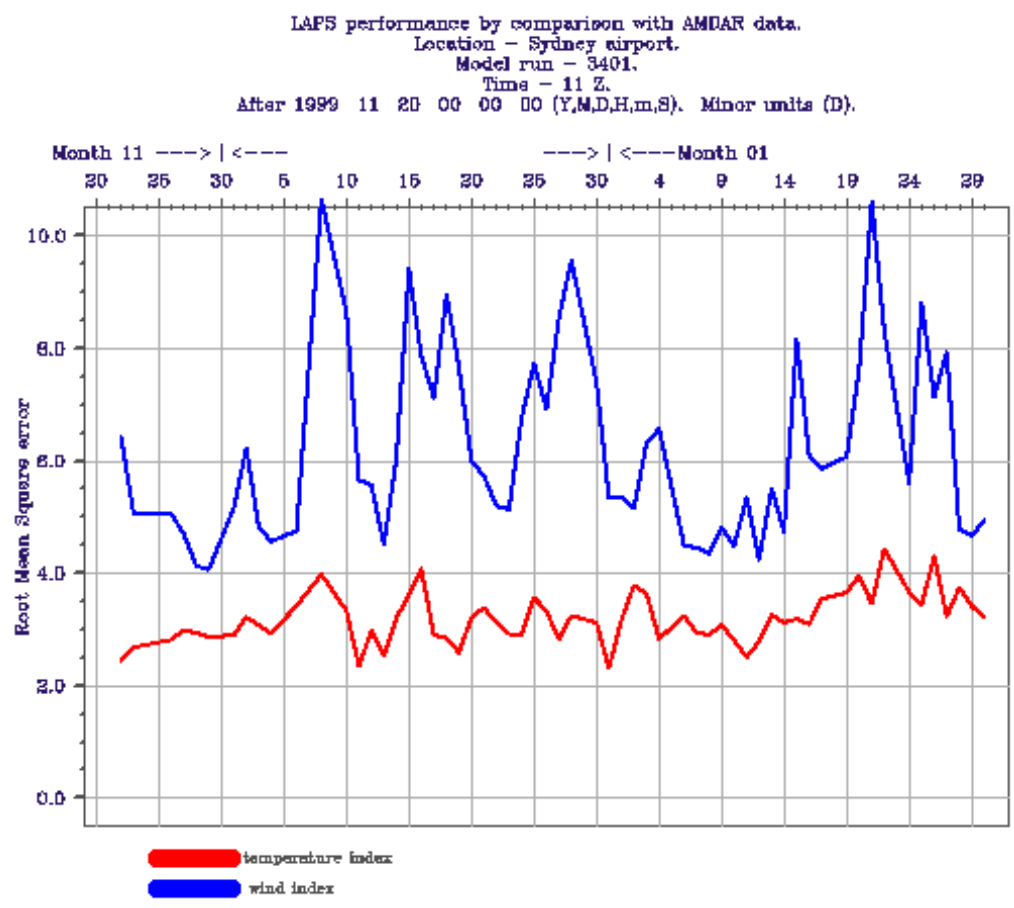

Figure 18. Time series of wind and temperature indices for the NSW domain. The wind index is the RMS vector wind error; the temperature index is the RMS temperature error. The calculations are based on AMDAR/LAPS comparison for flights to and from Sydney Airport and include all heights. 


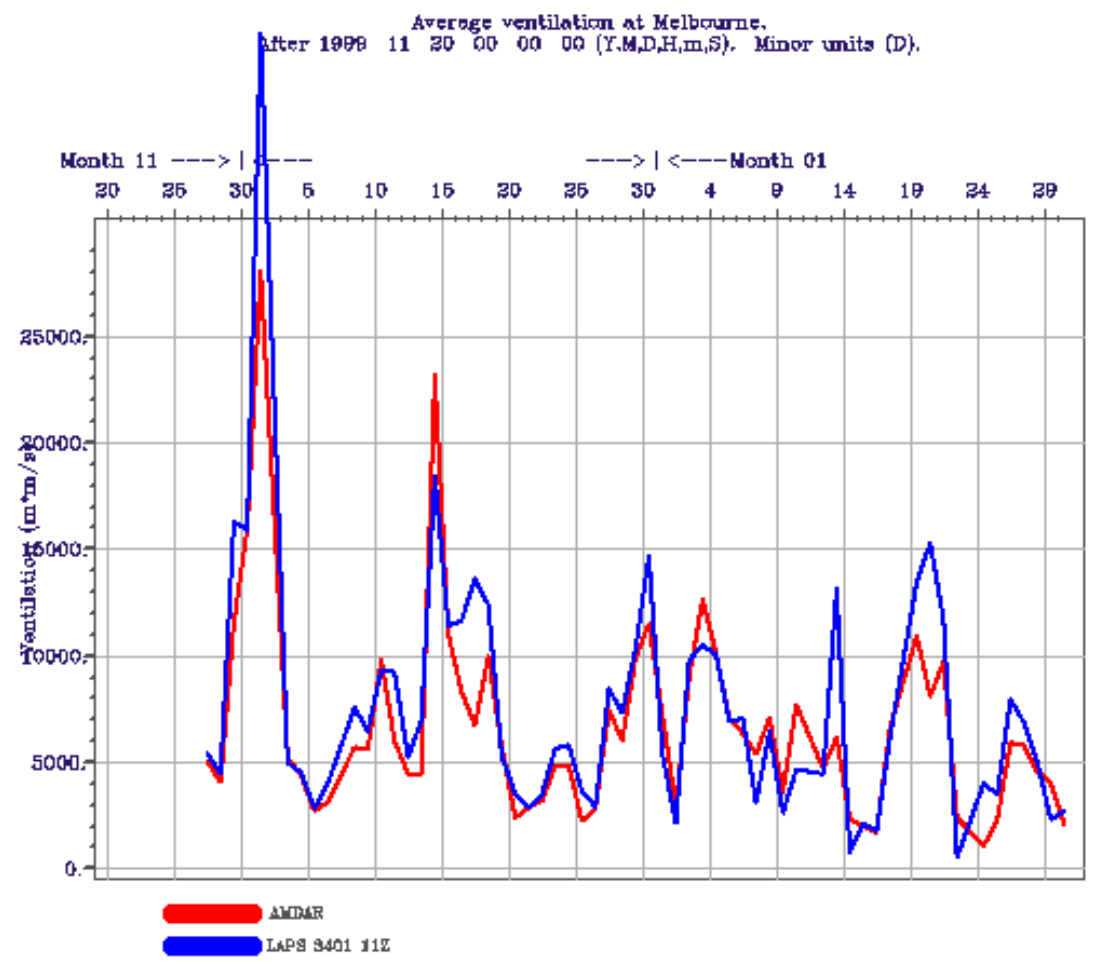

Figure 19. Comparison of time series of mean ventilation at Melbourne Airport for measured data (AMDAR) and predicted values (LAPS).

Averrage verntilation at 5 ydney.

Atter 198911 30 00 on oO ( $Y, M, D, H, m, S)$. Minor units (D).

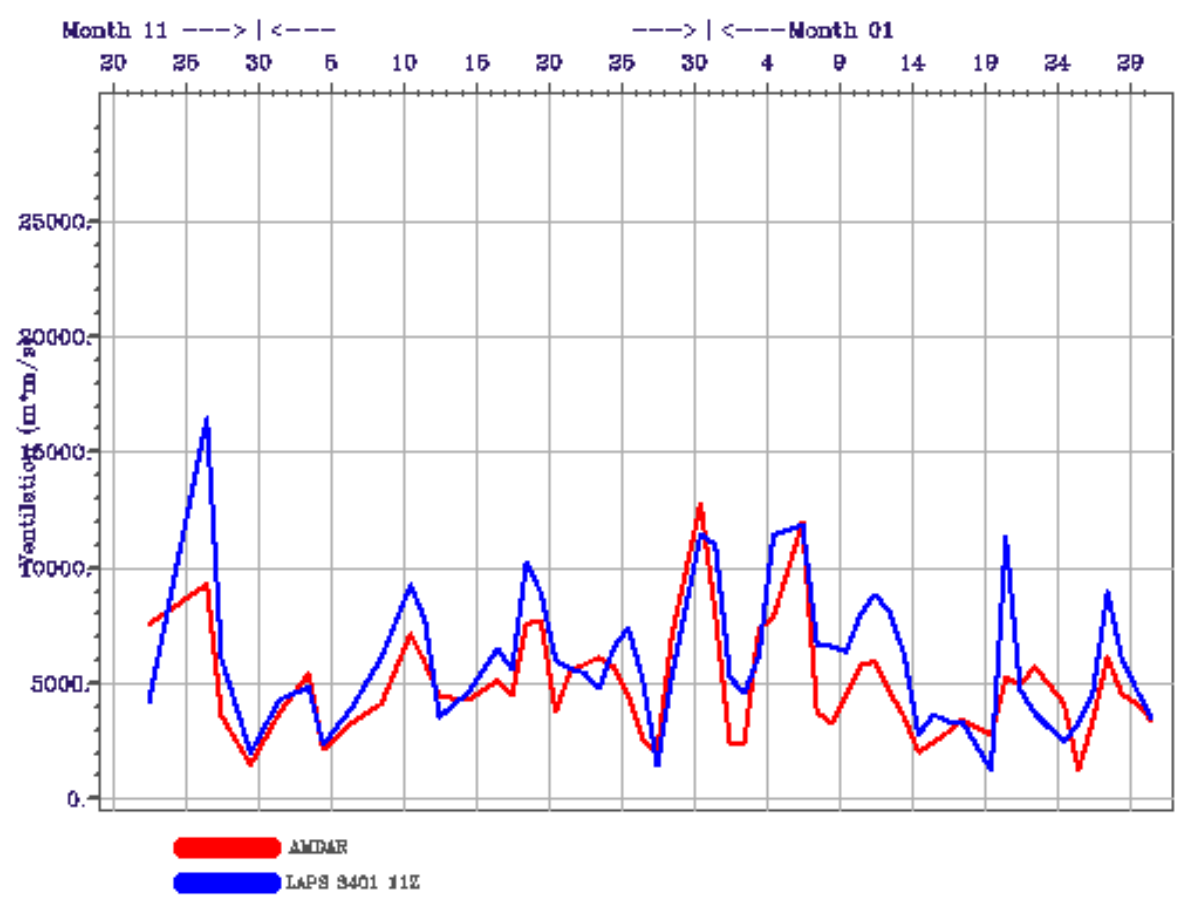

Figure 20. Comparison of time series of mean ventilation at Sydney Airport for measured data (AMDAR) and predicted values (LAPS). 
CSIRO Atmospheric Research

$3^{\text {rd }}$ Progress Report

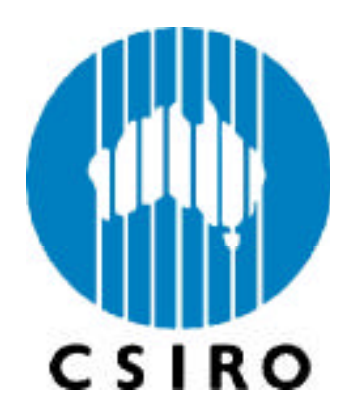




\title{
$3^{\text {rd }}$ Progress Report- February 2000
}

\author{
Martin Cope ${ }^{1,2}$ and Sunhee Lee ${ }^{1}$ \\ ${ }^{1} \mathrm{CSIRO}$ Atmospheric Research, ${ }^{2} \mathrm{CSIRO}$ Energy Technology
}

\section{Air quality modelling component.}

\section{Introduction}

The air quality modelling team of the Australian Air Quality Forecasting System (AAQFS) project has the task of developing and testing a comprehensive, state-of-theart chemical transport model (CTM). The model is required to generate twice-daily, 36hour forecasts of air pollution at resolutions sufficient to discriminate between the suburbs within an urban area. A pilot forecasting system, comprising available modelling components and emissions data, has been generating forecasts in Melbourne and Sydney for more than 18 months. These data have been archived and analysed in order to highlight areas in which significant development would be required during the development of a demonstration system. Data from the pilot system have also been used to identify a suite of case studies, which are required for testing purposes throughout the development phase. The pilot forecasting system also formed the basis for a prototype system, from which the final demonstration system is being constructed. Some output from the prototype system was presented at the end of the last reporting period. This report briefly documents further progress made towards the development of the demonstration system, and discusses the outcomes of a comparison of forecast and observed ozone concentrations for one of the Sydney-based case studies.

\section{Status}

During the reporting period, work has continued on the development and refinement of the prototype chemical-transport model (CTM), on the expansion and operation of the AAQFS web site, on improving the reliability of the systems used for accessing data from the state environment authorities, on the design of the archiving system, and on the development of a PC-based graphical display system. We have also continued with the evaluation of system performance, and have undertaken a detailed analysis of model forecasts for ozone episode observed in Melbourne on 10 December 1998, and a multiday Sydney-based ozone episode (peak 1-hour $\mathrm{O}_{3}>80 \mathrm{ppb}$ observed 9-14 December 1998). Our analysis of the air quality for the Melbourne event is included in the Bureau of Meteorology report- LAPS and the Australian Air Quality Forecasting System. In this report, we review results pertaining to three days (11-13 December) of the Sydney photochemical smog episode.

Sydney air quality episode. A discussion of the meteorological conditions that prevailed during this episode is provided in the Bureau of Meteorology' s progress report (presented elsewhere in this document). Critical to the formation of the photochemical smog was the presence of high ambient temperatures, low mixing depths and ventilation rates, and a low-level flow pattern which sometimes resulted in the recirculation of the previous day' s pollutants over the Sydney basin (see Figure 1 for a map of the Sydney modelling sub-domain). 
The importance of initialising the CTM to incorporate the effect of pollutant recirculation is illustrated in Figure 2, where observed and forecast daily peak 1-hour ozone concentrations have been plotted for December 1998. The base-case ozone forecasts were generated by the pilot forecasting system using a version of the CTM (CTM-GRS) that incorporates the Generic Reaction Set (GRS; Azzi et al. 1992), a highly condensed ( 7 species and 7 reactions) photochemical transformation mechanism featuring minimal computational overheads. The forecasts were initialised at 1100 UTC each day with spatially homogeneous (in the horizontal) pollutant fields which are representative of continental clean-air conditions (a 'cold start'). As can be seen from Figure 2, peak ozone concentrations for the period 9-14 December 1998 were strongly underpredicted when the system was operated in a cold start mode. However, the forecasts for 11-13 December are considerably improved when the CTM is initialised using the forecast pollution field for the previous day (a 'warm start'). This is particularly apparent for 13 December 1998 where the forecast ozone concentration peak increased from $90 \mathrm{ppb}$ to $124 \mathrm{ppb}$ (compared to $127 \mathrm{ppb}$ observed).

The third set of results in Figure 2 corresponds to warm start forecasts generated using a version of the CTM in which the GRS mechanism was replaced by a comprehensive photochemical transformation mechanism (CTM-LCC; Lurmann, Carter, Coyner mechanism; Lurmann et al. 1987). The LCC mechanism (35 species, 106 reactions), is able to realistically simulate a wider range of conditions than GRS, but requires considerably greater computational resources. Note that one of the goals of the forecasting project is to develop an enhanced version of GRS that is able to simulate a wider range of conditions, but at a fraction of the computational cost of LCC and other contemporary, comprehensive photochemical transformation mechanisms (see progress report by CSIRO Energy Technology, this document).

Plots of the forecast (CTM-GRS; warm start), ground-level concentration isopleths of oxides of nitrogen $\left(\mathrm{NO}_{\mathrm{x}}\right)$ and ozone $\left(\mathrm{O}_{3}\right)$ for hours 0900 EST $($ Eastern Standard Time $=$ GMT + 10) and 1500 EST of 11-13 December 1998 respectively are shown in Figures 3-8. The plots are for the entire CTM computational domain, which extends from north of Muswellbrook, to the south of Wollongong. At hour 0900 EST on 11 December, (Figure 3), the modelled overnight north-northeasterly flows have resulted in the transport of the Newcastle plume into northern Sydney, and the transport of the Sydney plume to seaward of Wollongong. The CTM then developed a photochemical smog plume within the northeasterly sea breeze, which was transported over the southern, Inland Region (see Figure 1 for description of air pollution sub-regions) of the Sydney basin. Peak ozone concentrations of 70-80 ppb were forecast to be present within the modelled region at hour 1500 EST on 11 December (Figure 4).

Northerly flow also occurred at the coast overnight of 11-12 December, however inland flows aloft were from the west-southwest, resulting in the recirculation of the previous day' s air mass over the Sydney region. This is illustrated in Figure 5 by the presence of a 40-50 ppb ozone plume to the west of Sydney at hour 0900 EST on 12 December. The combination of fresh photochemical smog precursor emissions and aged photochemical smog within the recirculated air mass resulted in a more intense ozone plume developing within the sea breeze on the afternoon of 12 December (Figure 6). 
The pattern of overnight recirculation is continued into 13 December, with the CTM predicting the fumigation of aged photochemical smog to the surface along the inland region of the Sydney basin (Figure 7). The presence of a meso-low during the afternoon of 13 December resulted in a southerly flow pattern, which transported the ozone plume to the north-northwest. The edge of the ozone plume was forecast to pass over the Newcastle and Hunter Valley regions.

Although the forecasting system has done reasonably well in reproducing the airshed peak ozone concentrations, it is also necessary to ascertain how well the system has performed in forecasting the diurnal variation of ozone at different localities (i.e. suburb-level forecasts). This is investigated further in Figures 9-14 where plots of observed and forecast 1-hour ozone time series are shown for a number of the EPANSW monitoring sites. Forecasts from both CTM-GRS and CTM-LCC are shown. Note that the plots have been divided up on the basis of locality, with Figure 9 containing plots for monitoring sites in/around Newcastle, Figure 10- Wollongong (south east Coastal Region), Figure 11- southern Inland Region, Figure 12- Eastern Region, Figure13-Central Region and Figure 14- Inland Region. The following outcomes are noted.

1. The forecasting system has performed well in reproducing the ozone peak observed in the Newcastle region (Figure 9- Beresfield and Wallsend) on 13 December (hours 48-71). This is a very positive outcome given that the peak appears to be caused by a combination of local photochemical production and transport of the Sydney plume within the meso-low. Note the differences between the forecasts of CTM-GRS and CTM-LCC for 10 December (hours 0-23) and 11 December (hours 24-47).

2. CTM-GRS has performed well in predicting the generally low concentrations observed in the Illawarra (Figure 10- Kembla Grange and Albion Park). The match between observed and forecast concentrations is particularly good at the Kembla Grange monitoring station. On the other hand, CTM-LCC has overpredicted ozone concentrations for the first two days of the modelled period.

3. Observed ozone concentrations in the southern Inland Region (Figure 11- Bargo and Oakdale) have been forecast with good skill by CTM-GRS on 12 and 13 December and within the sea breeze on the afternoon of 11 December. However, the pre-sea breeze peak observed on 11 December has been underpredicted by the CTM-GRS model. It is nevertheless pleasing to note that the forecasting system has correctly predicted that the highest concentrations would occur in this region on the first and second days of the modelled period, while also correctly predicting that the highest concentrations would occur in Newcastle on the second and third days. Note that CTM-LCC generally performs better than CTM-GRS at these two sites.

4. Peak ozone concentrations are underpredicted in the Central Region by CTM-GRS but reasonably well matched by CTM-LCC (Figure 13- Lidcombe and Westmead). This result is also apparent for Bringelly and St Mary's monitoring station in the Inland Region (Figure 14). In the case of CTM-GRS it can be seen that, although the peak observed concentrations have been forecast with reasonable skill on 12 December (hours 24-47), peak concentrations are strongly underpredicted on 13 December. CTM-LCC also underpredicted peak ozone concentrations on the latter day. One likely reason for the underpredictions is shown in Figure 15, where the 
position of the Sydney ozone plume at hour 1400 EST has been plotted (CTM-GRS model). It can be seen that, although the forecasting system has correctly predicted the presence of high concentrations of ozone, the centroid of the plume is located to the north of the monitoring stations. This suggests that the forecast plume trajectory may be slightly in error. Such an outcome is not unexpected, given the complexity of the meteorological flows that were present over the region during 13 December 1998.

The outcome noted in 4 above highlights the difficulties involved in accurately forecasting air pollution concentrations down to suburb levels. This is particularly the case for photochemical smog during the summer period, when the plume trajectory will often be influenced by the timing and passage of sea-breeze fronts and the evolution of other mesoscale circulation patterns.

The outcomes of the comparison discussed above may also be quantified using a range of statistical measures. Typically these may include the percentage of hours that a forecast concentration lies within a factor of two of the observed concentration, the percentage of hours that the observed concentrations were underpredicted, the bias, the standard deviation of the residuals, and the gross error. Further details regarding the application of these and other measures of performance to photochemical airshed modelling may be found in Tesche et al. (1990). These statistical measures have been calculated for the current three-day case study for both the CTM-GRS and CTM-LCC models and are presented in Table 1. Note that the forecast and observed concentrations have been paired according to four criteria.

1. Matching in time and space (ST). Compare the observed concentration with the modelled concentration interpolated from the four nearest cells of the CTM computational domain. Match the time of the observed and modelled concentrations.

2. Matching in time only $(T)$. Compare the observed concentration with the best CTM prediction within a radius of $6 \mathrm{~km}$ of the observation point. Match the time of the observed and modelled concentrations.

3. Matching in space only $(S)$. Compare the observed concentration with the modelled concentration interpolated from the four nearest cells of the CTM computational domain. Take the best CTM prediction within \pm 1 -hour of the observation time.

4. Un-matched $(U)$. Compare the observed concentration with the best CTM prediction within a radius of $6 \mathrm{~km}$ of the observation point and within \pm 1 -hour of the observation time.

Note that the purpose of examining model performance for the various degrees of spatial and temporal matching is to explore the sensitivity of the forecast' $s$ accuracy to small spatial and temporal errors in the modelled concentration fields. A radius of $6 \mathrm{~km}$ and a time interval of 1 hour have been selected because the former can be considered representative of a reasonable suburb-level spatial scale, and because a temporal scale of 1-hour maximum is close to the maximum temporal resolution of the CTM. 
With respect to the data in Table 1, it can be seen that $85 \%$ of the observed ozone concentrations were matched to within a factor of two by CTM-GRS for the case of $S T$ matching. This increases to $99 \%$ when spatial/temporal constraints are relaxed.

However, the majority of the observed concentrations are underpredicted by CTM-GRS. This is apparent from the normalised bias, which ranges from $-26 \%$ to $-13 \%$. The normalised gross error lies within the range 15-32\%. The CTM-LCC performance is superior, with $98 \%$ of forecast ozone concentrations lying within a factor of two of the observed for the $S T$ criteria. Moreover, only $49 \%$ of the observed concentrations were underpredicted (ideal is 50\%). The normalised bias ranged from $6 \%(S T)$ to only $1 \%$ $(U)$ and the normalised gross error ranged from $23 \%(S T)$ to $5 \%(U)$.

Tesche et al. (1990) suggests that the absolute value of the bias should fall below the range $5-15 \%$ and the gross error should fall below $30-35 \%$ before the performance of a photochemical airshed model is considered suitable for the purposes of scenario modelling for air quality management. Thus it can be seen that the performance of CTM-GRS lies above or just within the upper bound of this suggested performance envelope, and the CTM-LCC performance is considerably better than these criteria.

Long-term performance metrics As noted in the attached report from the Bureau of Meteorology, it is also useful to accumulate daily statistical performance measures for the purposes of determining trends in model performance, and for identifying conditions where model performance may be unusually poor. In addition to the use of these measures, we have found that a valuable indicator of model performance is the comparison of cumulative frequency distributions of observed and forecast air pollutant concentrations. This is highlighted in Figure 16 where cumulative frequency

distributions of observed and forecast 1-hour $\mathrm{NO}_{\mathrm{x}}$ concentrations for January 2000 have been plotted for EPANSW monitoring stations located at Rozelle, Campbelltown, Randwick and Lidcombe. From the plots it can be seen that the CTM has a tendency to overpredict observed $\mathrm{NO}_{\mathrm{x}}$ concentrations at Rozelle and at Randwick, while observed concentrations are underpredicted at Campbelltown. On the other hand, the CTM shows little bias at Lidcombe. Such information can be used to highlight potential errors in the emissions inventories and/or systematic errors in the forecast meteorology.

\section{Conclusions.}

Design and development work has continued on various components of the forecasting system over the reporting period. The forecasting system is run on a daily basis, generating 24-36 hour air quality forecasts for the NSW-east coast and Melbourne/Geelong regions. These forecasts are now routinely compared against observational data and the results archived for further analysis. Examples of two detailed case studies are presented in this report for episodes of above-background ozone concentrations in Melbourne and Sydney. These and other case studies will continue to be re-visited as further enhancements are made to the forecasting system.

\section{References}

Azzi M., Johnson G.J. and Cope M., 1992. An introduction to the Generic Reaction Set Photochemical smog mechanism. Proc. $11^{\text {th }}$ International Clean Air Conf., Brisbane, 510 July, 451-462. 
Hyde R., Young M.A., Hurley P.J. and Manins P.C., 1996. Metropolitan air quality study: Meteorology - Air Movements. Final report to New South Wale Environment Protection Authority.

Lurmann F.W., Carter W.P. and Coyner L.A., 1987. A surrogate species chemical reaction mechanism for urban scale air quality simulation models. Final report to U.S. Environment Protection Agency under Contract Number 68-02-4104.

Tesche T.W., Lurmann F.L. and Roth P.M., 1990. Improvement of procedures for evaluating photochemical models. Report to California Air Resources Board, Sacramento, $C A$.

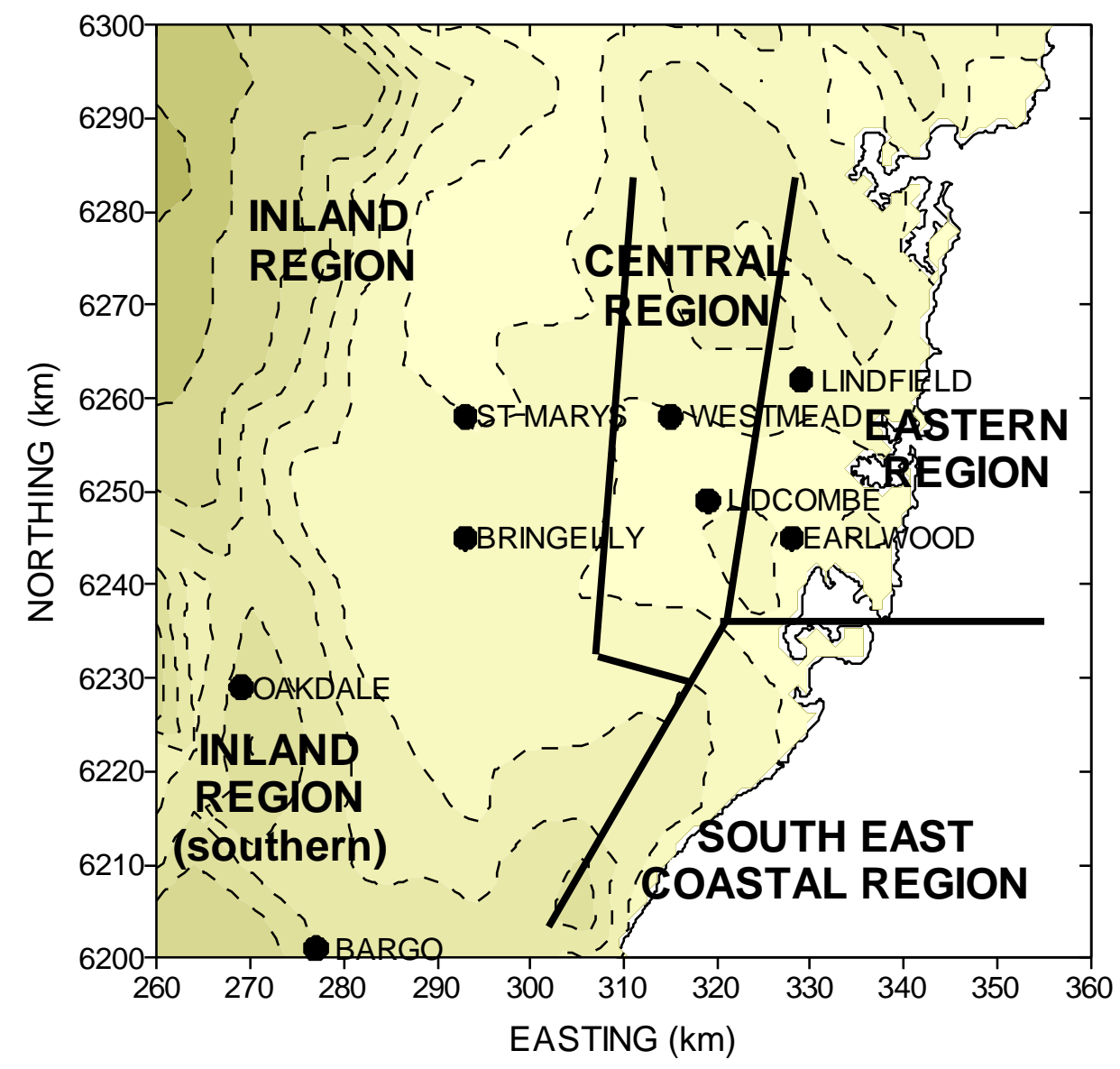

Figure 1: Map of the Sydney basin, showing sub-regions classified on the basis of characteristic photochemical smog patterns (refer to Hyde et al. 1996). Also shown are the localities of selected EPANSW monitoring stations. 


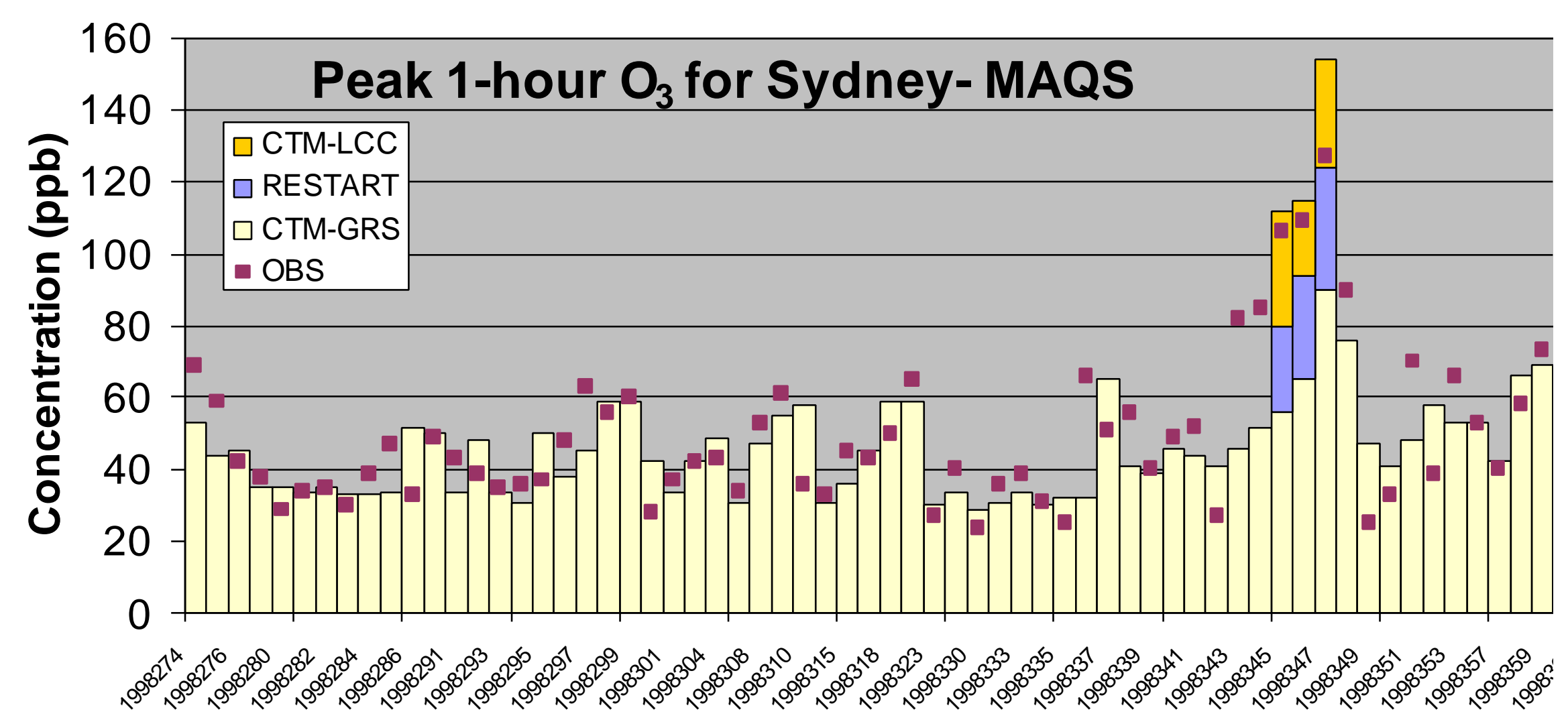

\section{Julian Day (OCT- DEC 1998)}

Figure 2: Observed (OBS) vs. forecast (CTM-GRS) peak 1-hour ozone concentration for the Sydney/lllawarra/Newcastle region for the period October-December 1998. Note that ' RESTART' indicates the increase in peak forecast ozone concentration when the model is initialised using pollution fields from the previous forecast as the initial concentration field. ' RESTART' runs were undertaken for the period 11-13 December (discussed in more detail in the text). CTM-LCC corresponds to the increase in peak concentrations when the fore cast was made using a larger, more comprehensive chemical transformation mechanism (see text). Days for which forecasts were not available have been omitted from the plot. 

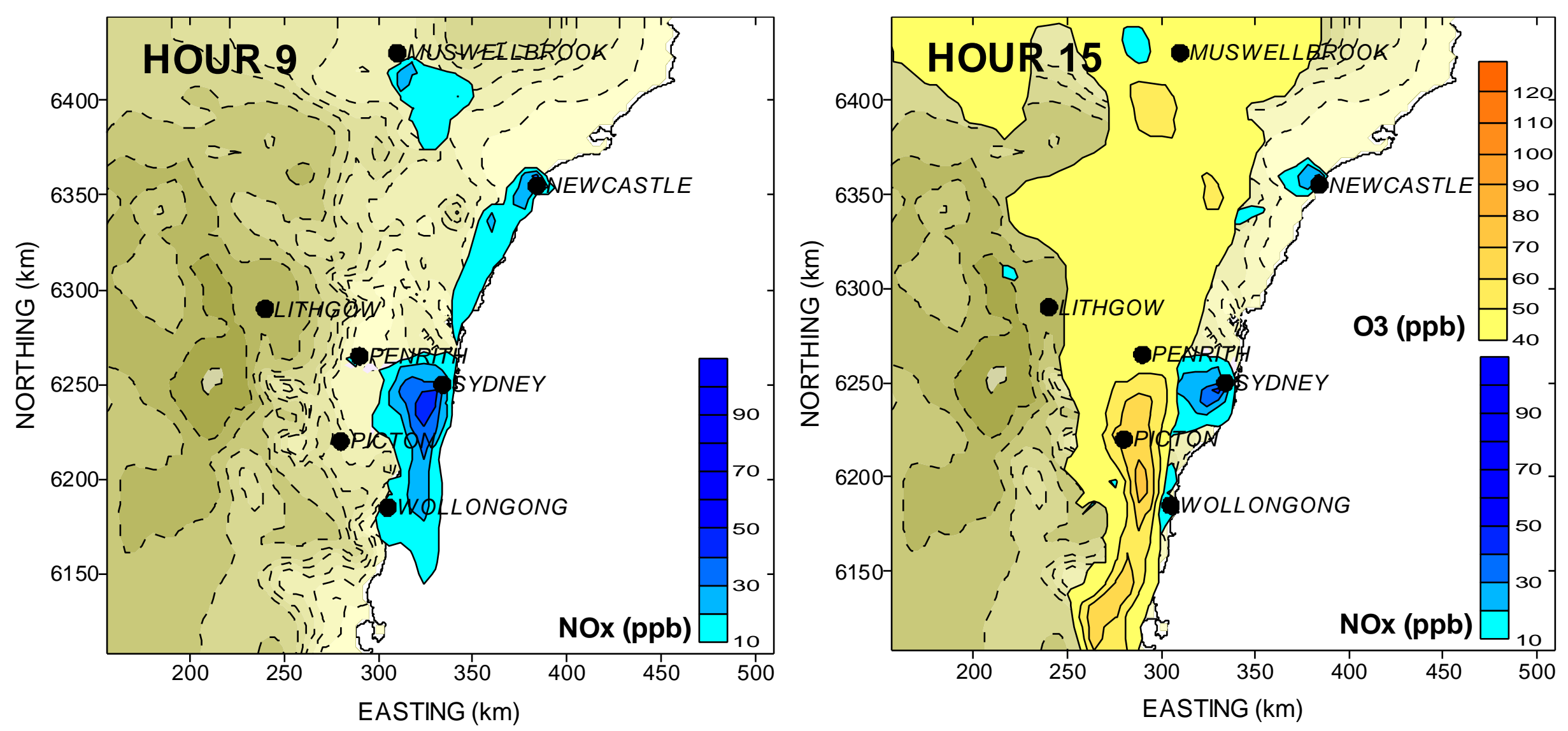

Figure 3: Forecast ground-level concentrations of $\mathrm{NO}_{\mathrm{x}}(\mathrm{ppb})$ for 0900 EST, 11 December 1998.

Figure 4: Fore cast ground-level concentrations of $\mathrm{NO}_{x}$ and $\mathrm{O}_{3}$ (ppb) for 1500 EST, 11 December 1998. 


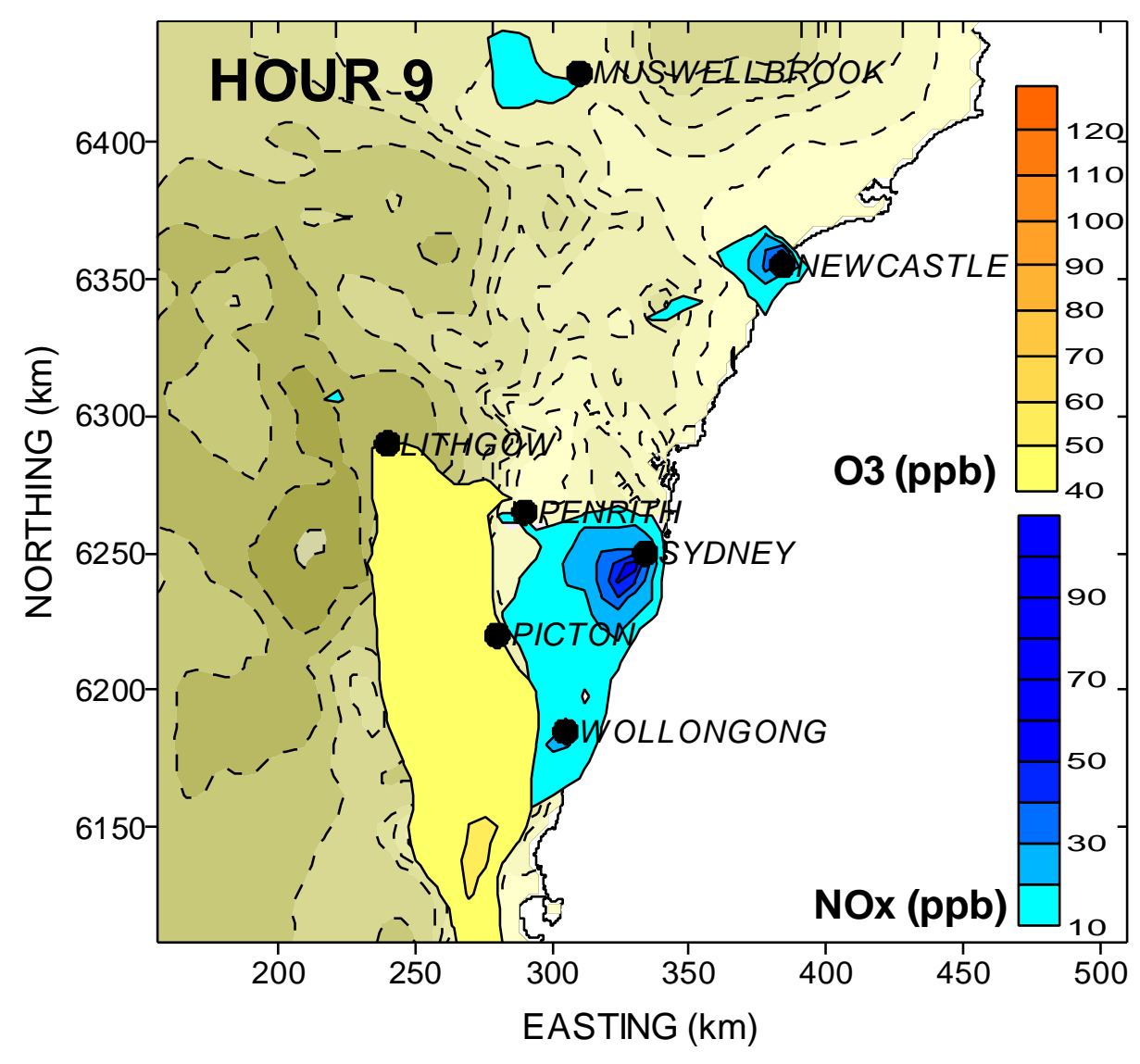

Figure 5: Forecast ground-level concentrations of $\mathrm{NO}_{\mathrm{x}}$ and $\mathrm{O}_{3}$ (ppb) for 0900 EST, 12 December 1998.

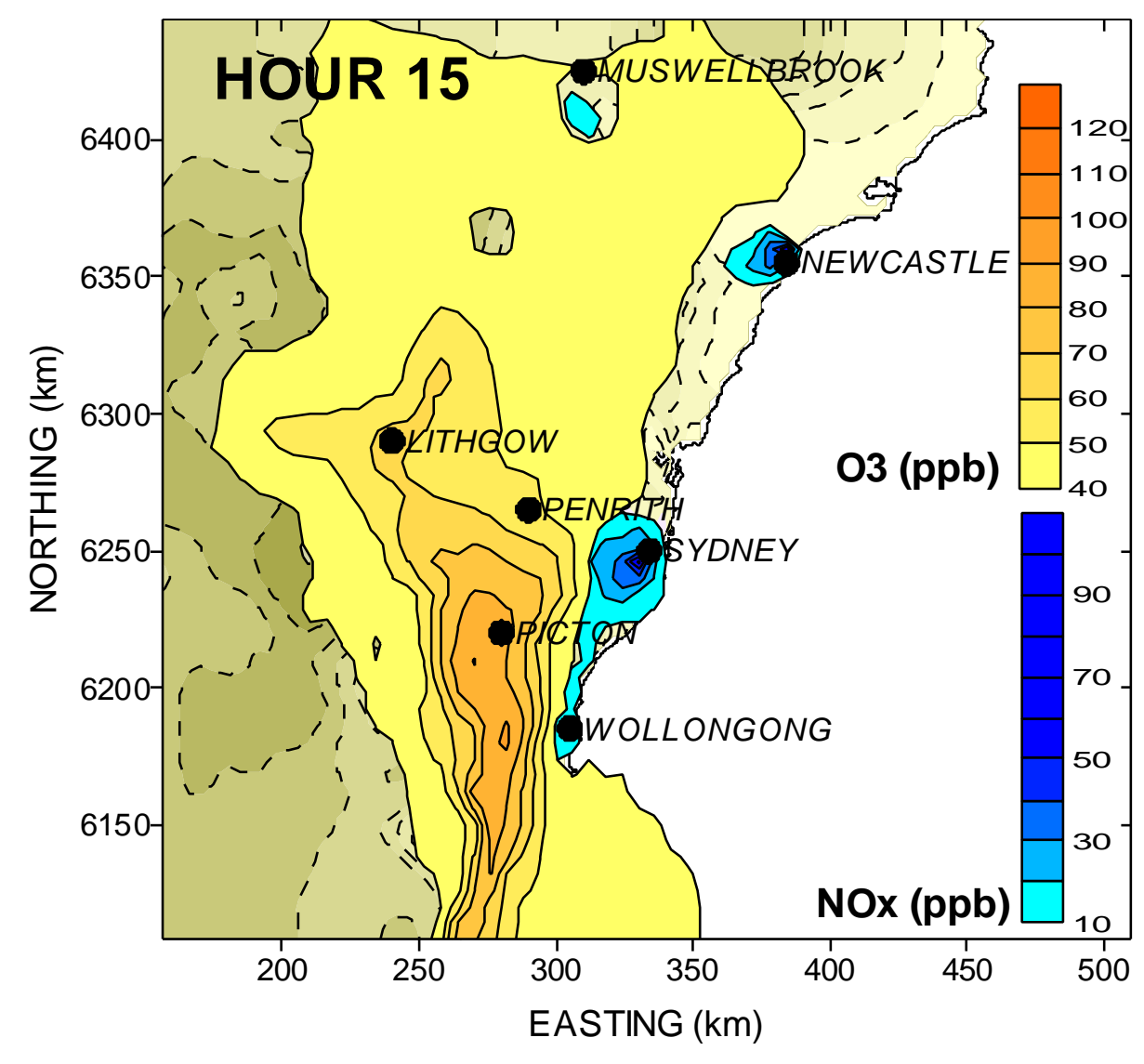

Figure 6: Forecast ground-level concentrations of $\mathrm{NO}_{\mathrm{x}}$ and $\mathrm{O}_{3}$ (ppb) for 1500 EST, 12 December 1998. 


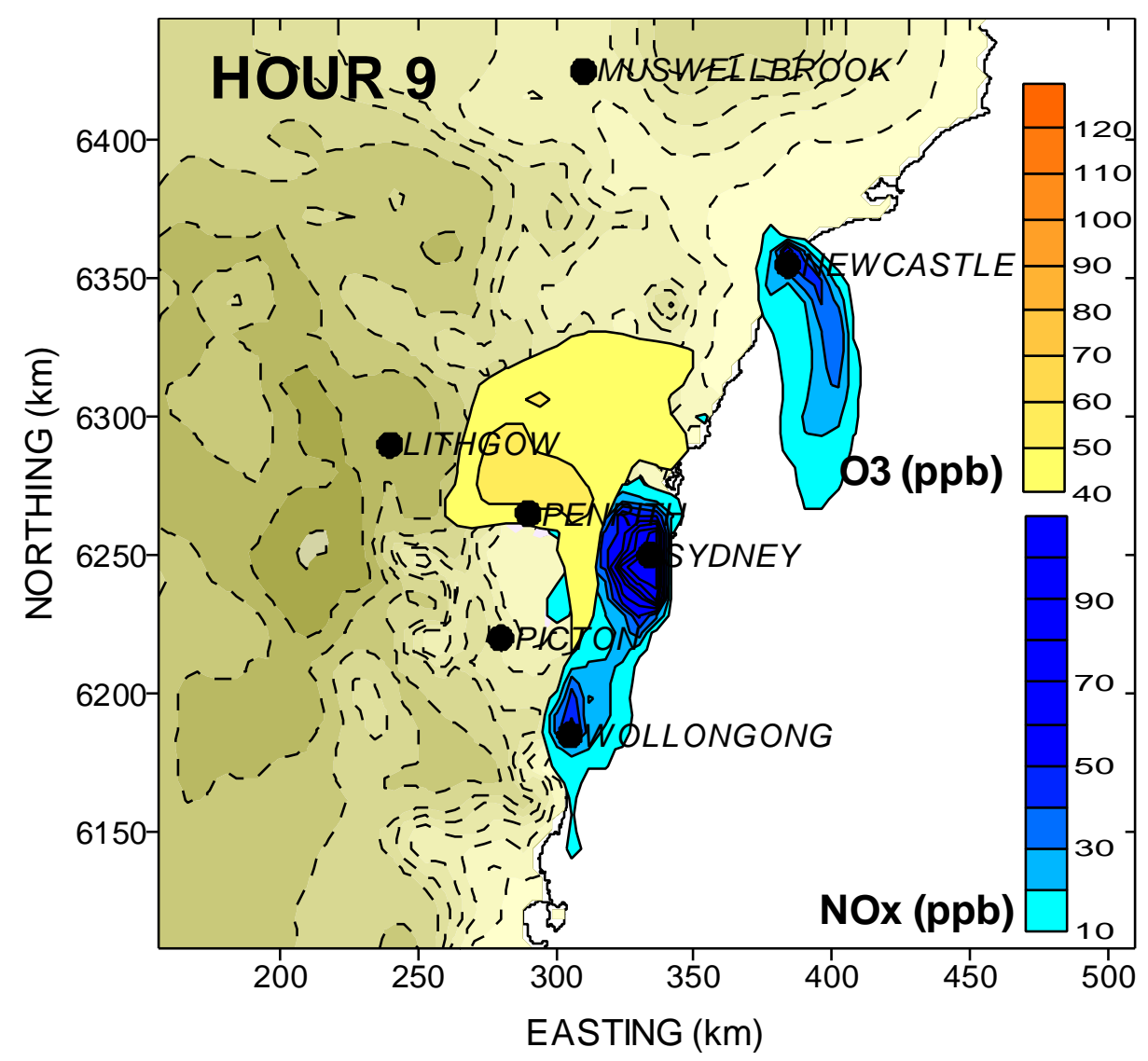

Figure 7: Forecast ground-level concentrations of $\mathrm{NO}_{\mathrm{x}}$ and $\mathrm{O}_{3}$ (ppb) for 0900 EST, 13 December 1998.

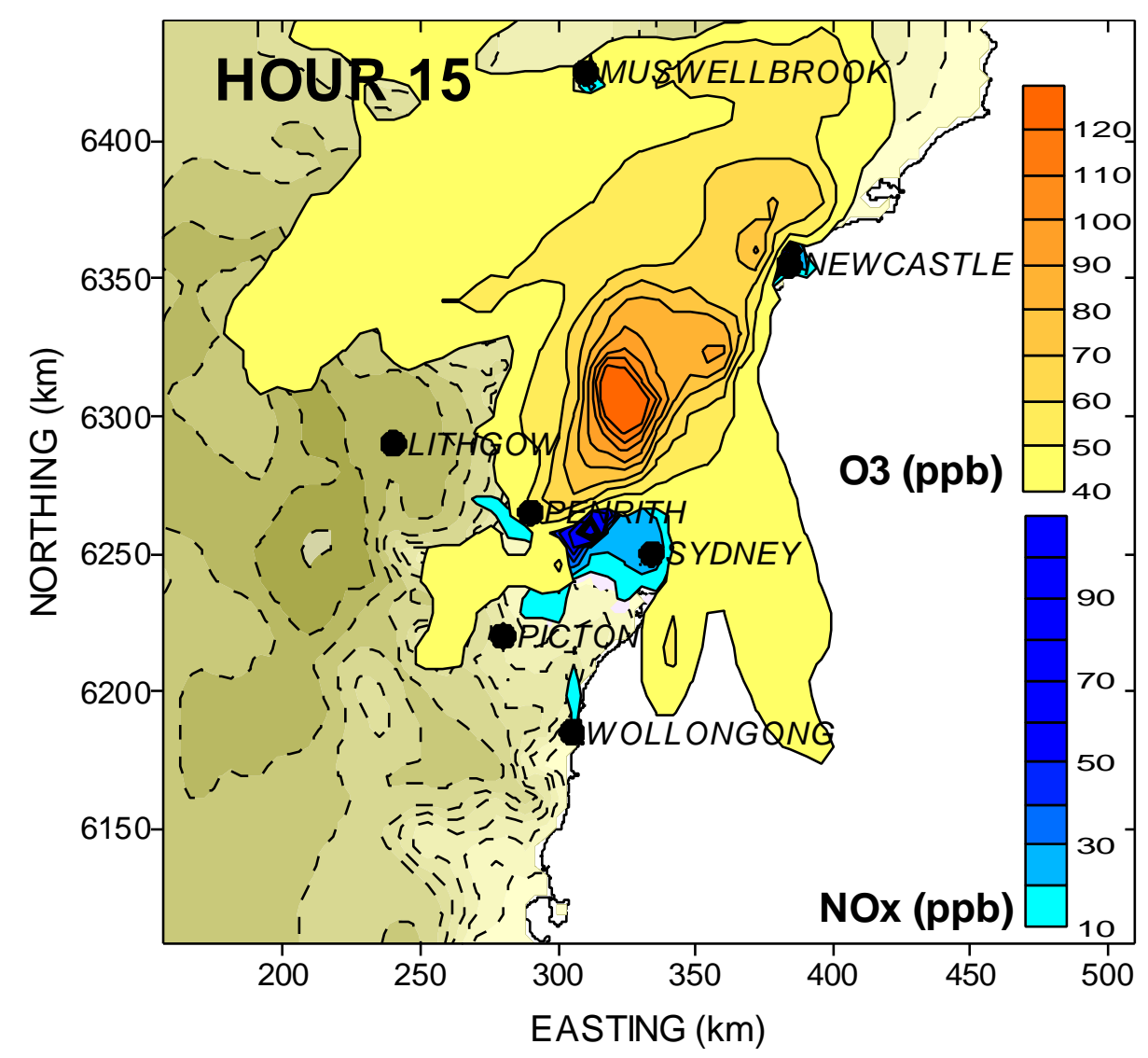

Figure 8: Forecast ground-level concentrations of $\mathrm{NO}_{x}$ and $\mathrm{O}_{3}$ (ppb) for 1500 EST, 13 December 1998. 


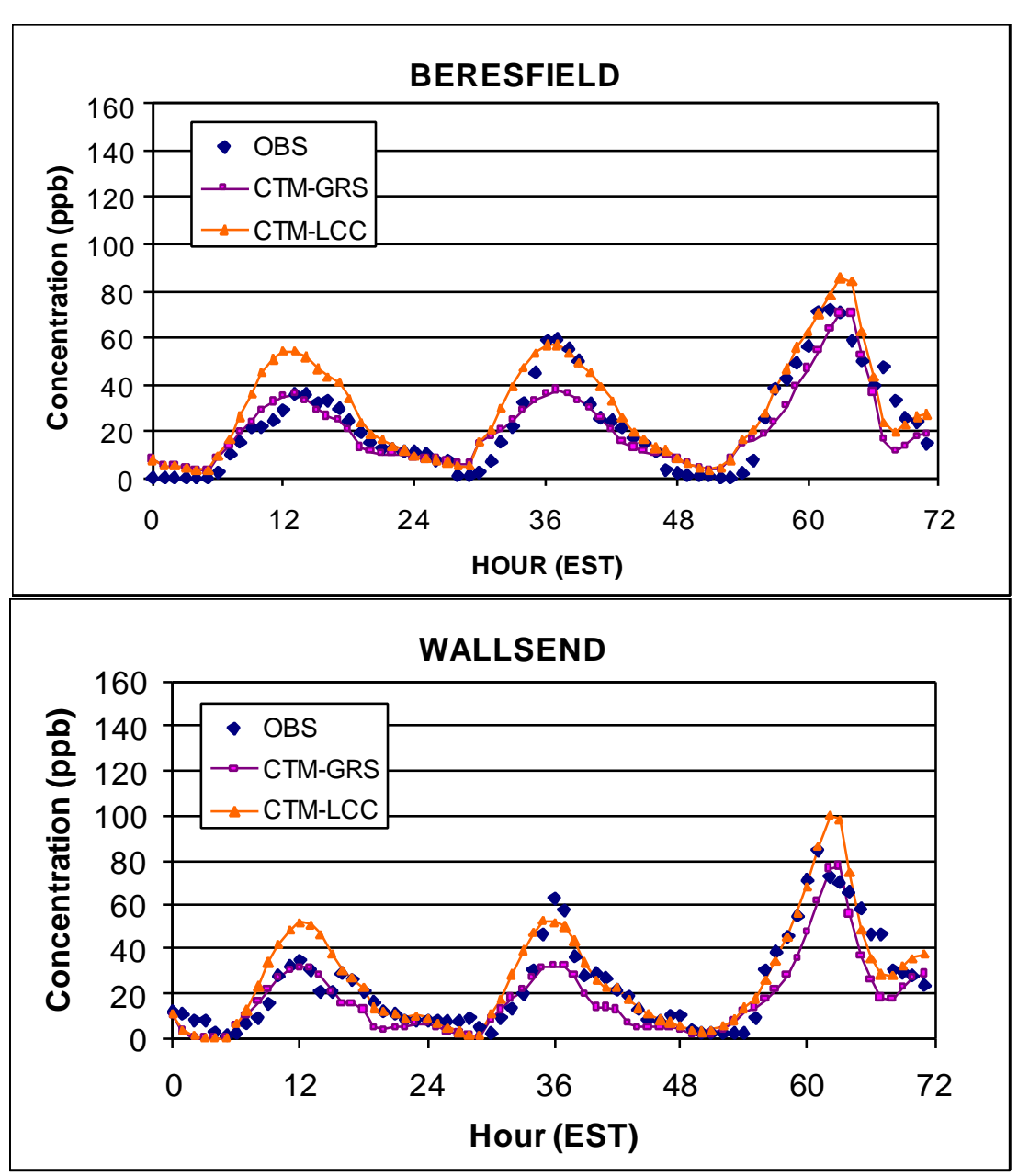

Figure 9: Time series of observed and forecast 1-hour ozone concentration for selected monitoring stations in the Newcastle Region.
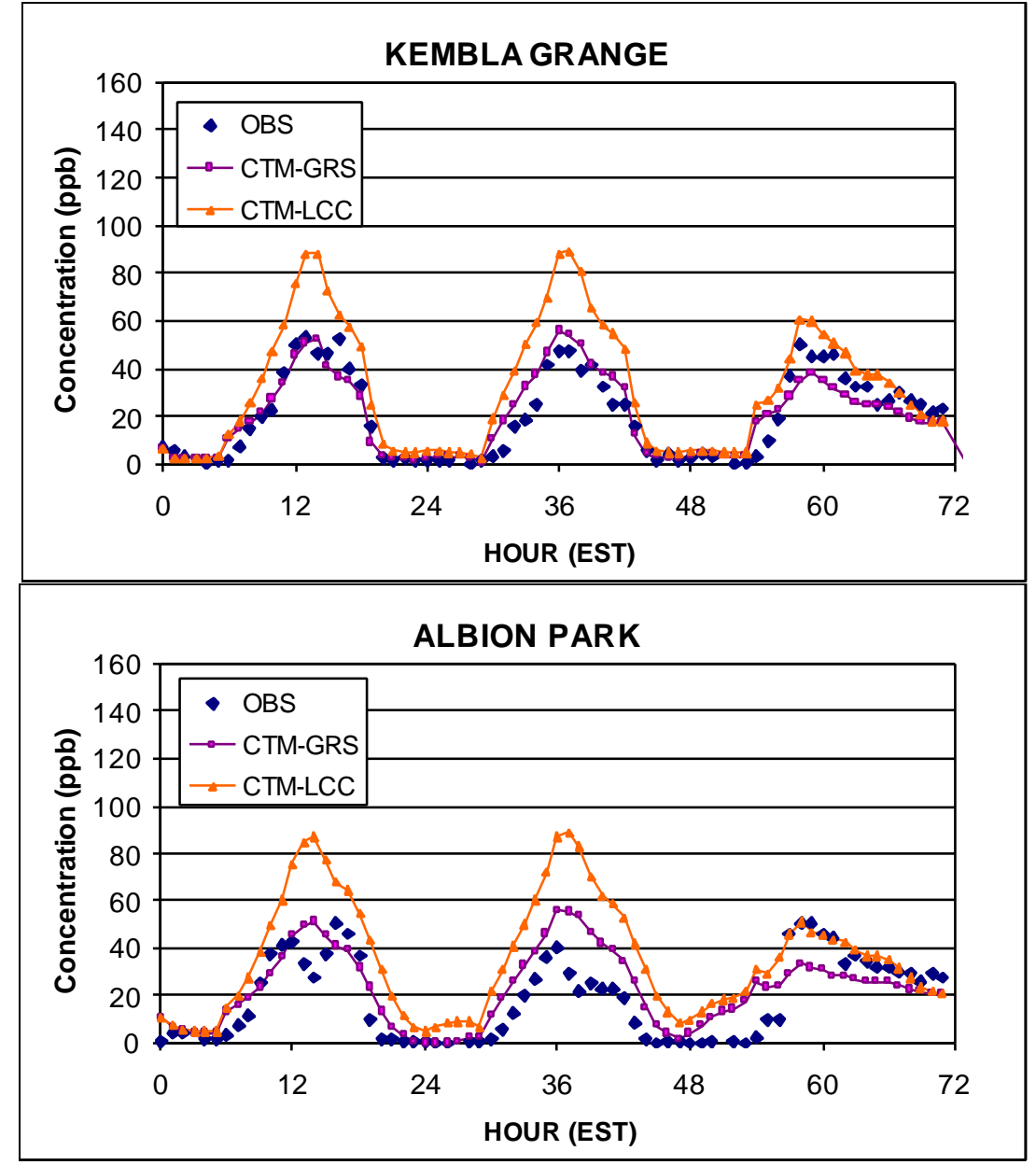

Figure 10: Time series of observed and fore cast 1-hour ozone concentration for selected monitoring stations in the Illawara Region. 

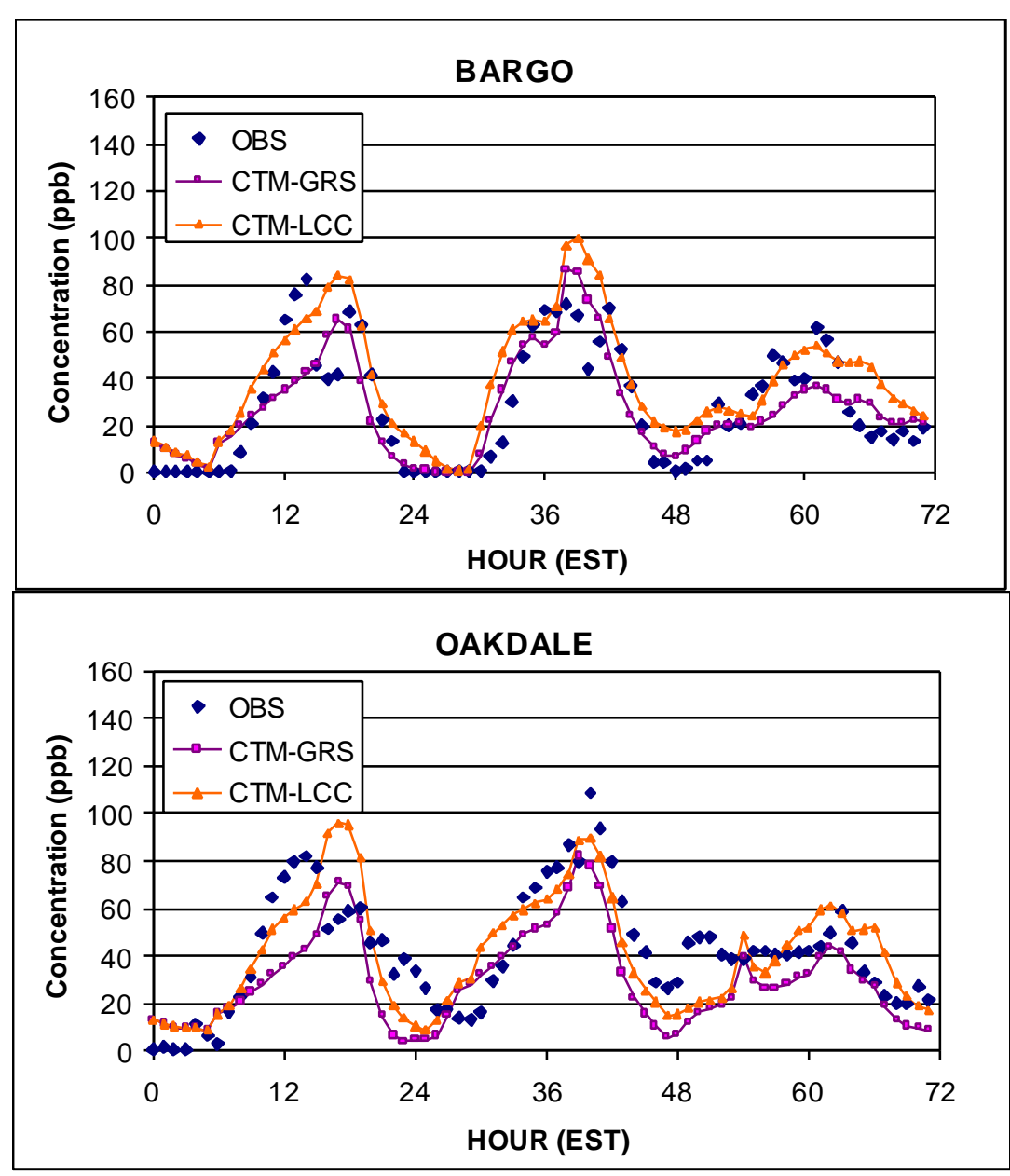

Figure 11: Time series of observed and forecast 1-hour ozone concentration for selected monitoring stations in the southern Inland Region (see Figure 1).
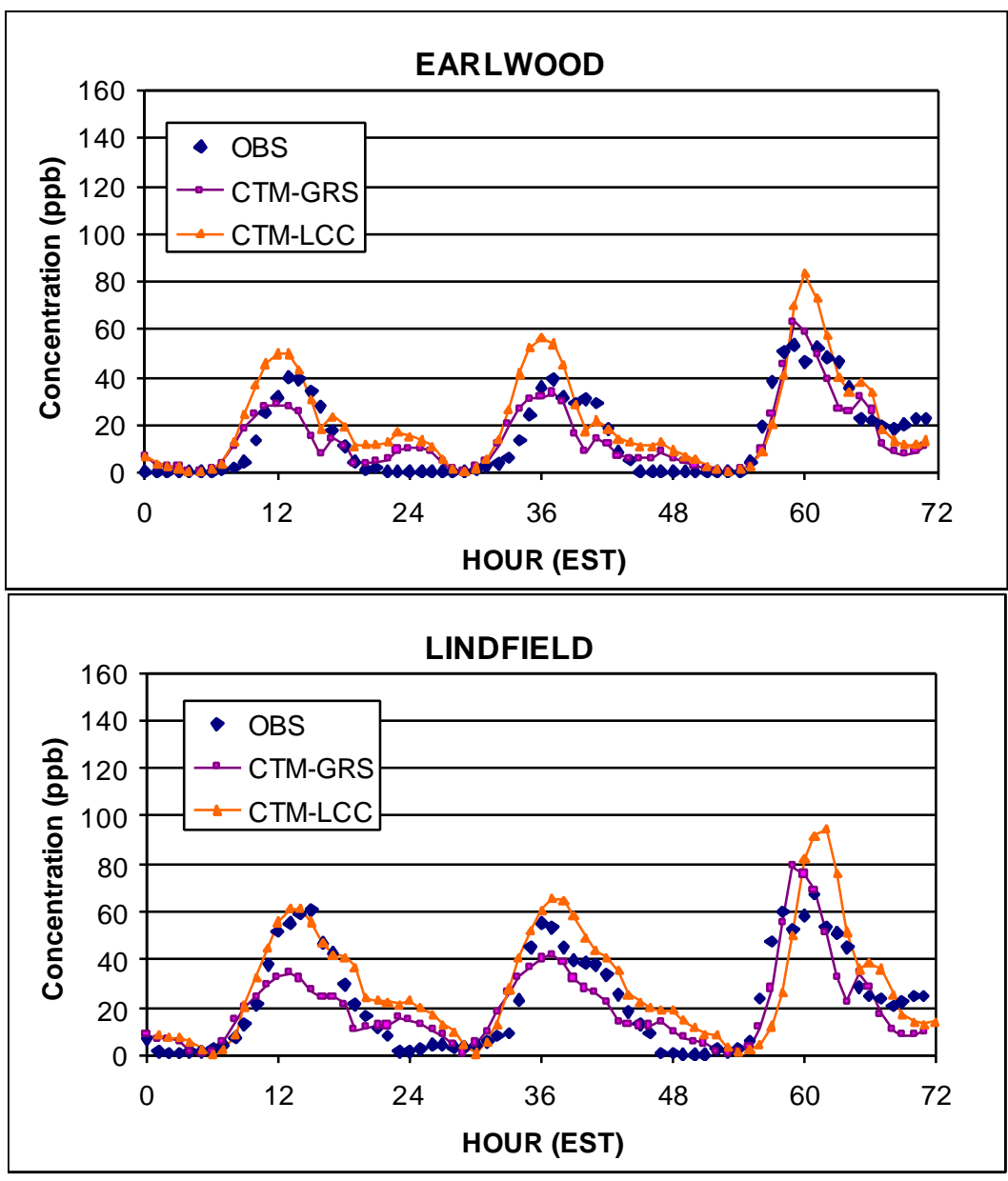

Figure 12: Time series of observed and forecast 1-hour ozone concentration for selected monitoring stations in the Eastern Region (see Figure 1). 

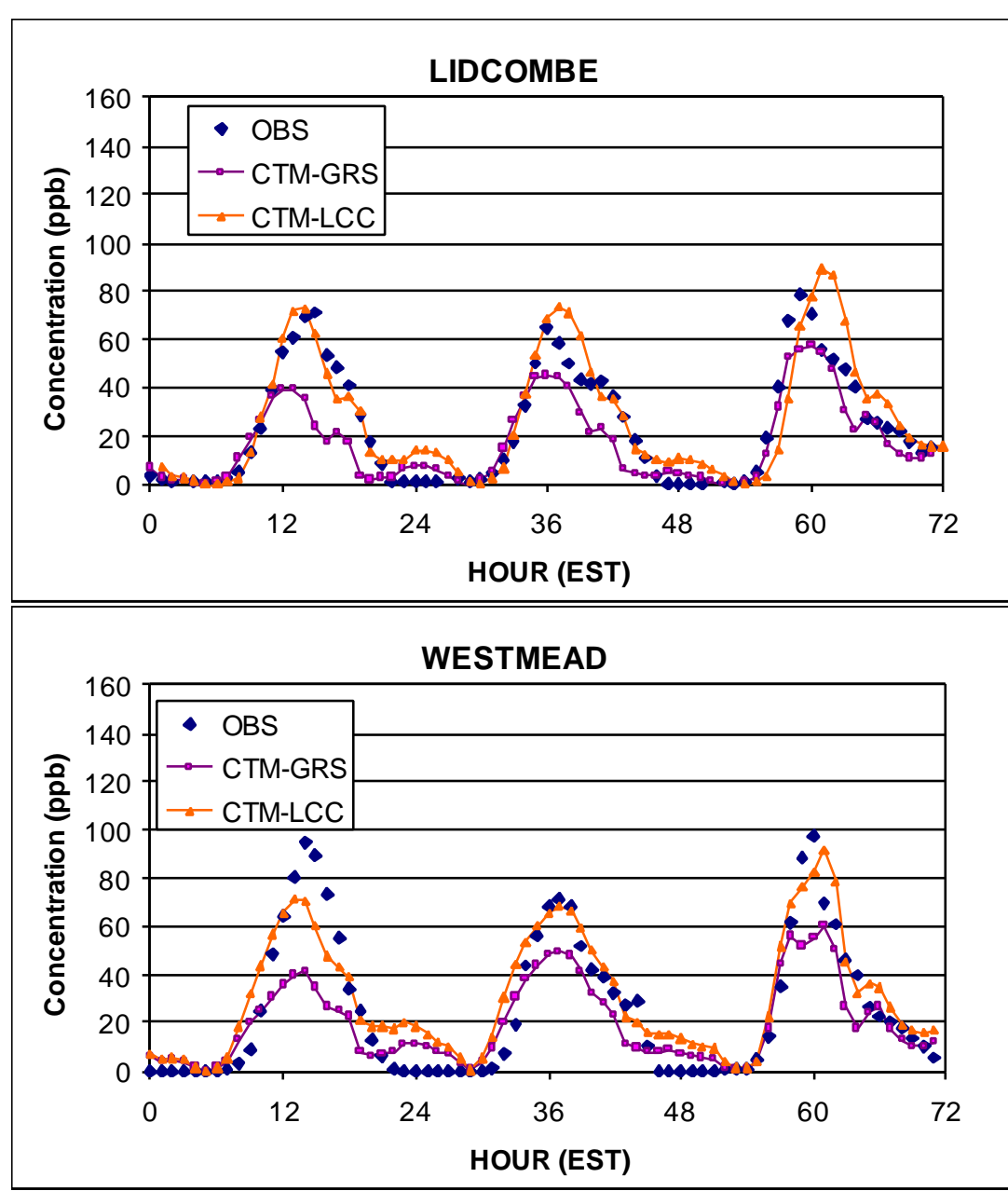

Figure 13: Time series of observed and forecast 1-hour ozone concentration for selected monitoring stations in the Central Region (see Figure 1).
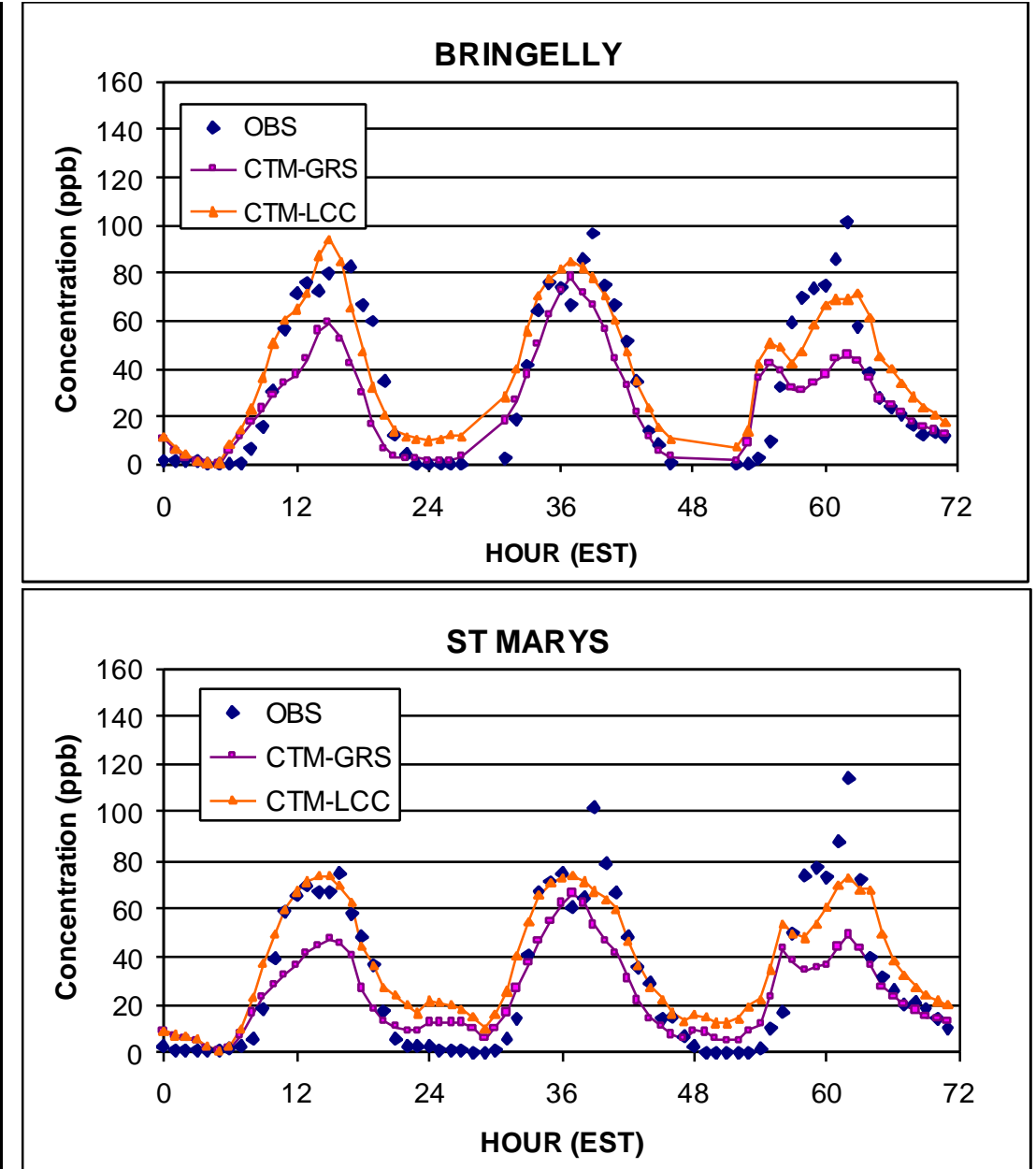

Figure 14: Time series of observed and forecast 1-hour ozone concentration for selected monitoring stations in the Inland Region (see Figure 1). 


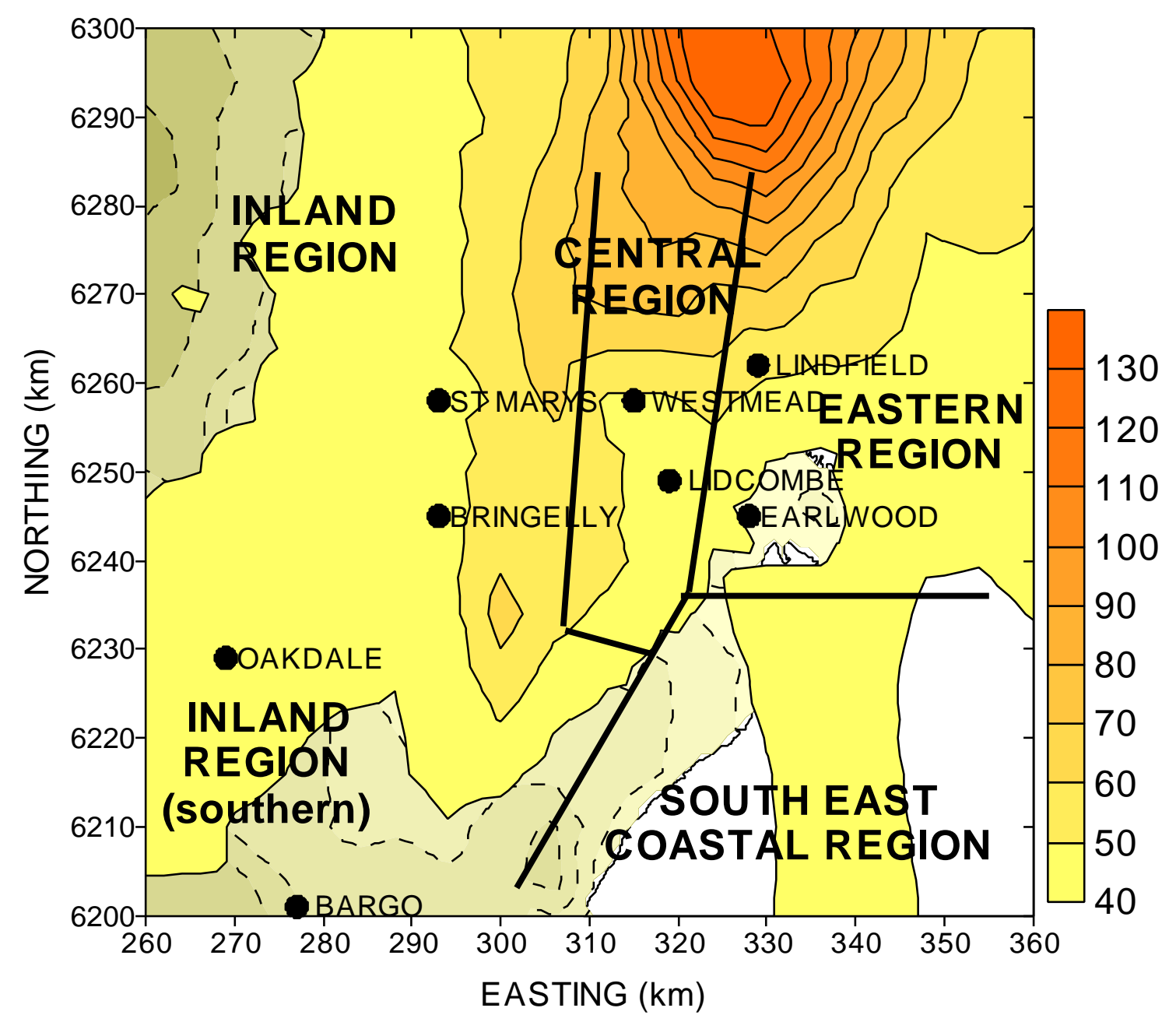

Figure 15: Forecast ground-level concentrations of $\mathrm{O}_{3}$ for $1400 \mathrm{EST}, 13$ December 1998. 
Table 1: Bias statistics for 1-hour ozone for the forecast period 11-13 December 1998. The pairing constraints are $s t$ :- observation and model forecast matched in time and space; $t$ :matched in time and best forecast within a $6-\mathrm{km}$ radius is chosen; $s$ :- matched in space and the best forecast within \pm 1 hour of the observation time is chosen; $u$ :- best forecast within a $6-\mathrm{km}$ radius and \pm 1 hour of the observation is chosen.

\begin{tabular}{|c|c|c|c|c|c|c|c|c|}
\hline \multirow[t]{3}{*}{ Statistical Measure $^{1}$} & \multicolumn{8}{|c|}{ Model Configuration (see text) } \\
\hline & \multicolumn{4}{|c|}{$\begin{array}{l}\text { CTM-GRS } \\
\text { Pairing type }\end{array}$} & \multicolumn{4}{|c|}{$\begin{array}{l}\text { CTM-LCC } \\
\text { Pairing type }\end{array}$} \\
\hline & st & $\mathrm{t}$ & s & $\mathrm{u}$ & st & $\mathrm{t}$ & $\mathrm{s}$ & $\mathrm{u}$ \\
\hline $\begin{array}{l}\text { Percentage within a factor } \\
\text { of } 2\end{array}$ & 85 & 96 & 94 & 99 & 98 & 100 & 99 & 100 \\
\hline $\begin{array}{l}\text { Percentage under } \\
\text { predicted }\end{array}$ & 87 & 82 & 85 & 78 & 49 & 48 & 52 & 50 \\
\hline Bias (ppb) & -17 & -12 & -13 & -9 & 1 & 0 & 0 & 0 \\
\hline Normalized bias (\%) & -26 & -18 & -20 & -13 & 6 & 3 & 1 & 1 \\
\hline$\sigma$ of residuals (ppb) & 17 & 14 & 15 & 12 & 17 & 10 & 11 & 6 \\
\hline Gross error (ppb) & 20 & 14 & 15 & 10 & 13 & 7 & 8 & 3 \\
\hline $\begin{array}{l}\text { Normalized gross error } \\
(\%)\end{array}$ & 32 & 21 & 23 & 15 & 23 & 12 & 13 & 5 \\
\hline
\end{tabular}



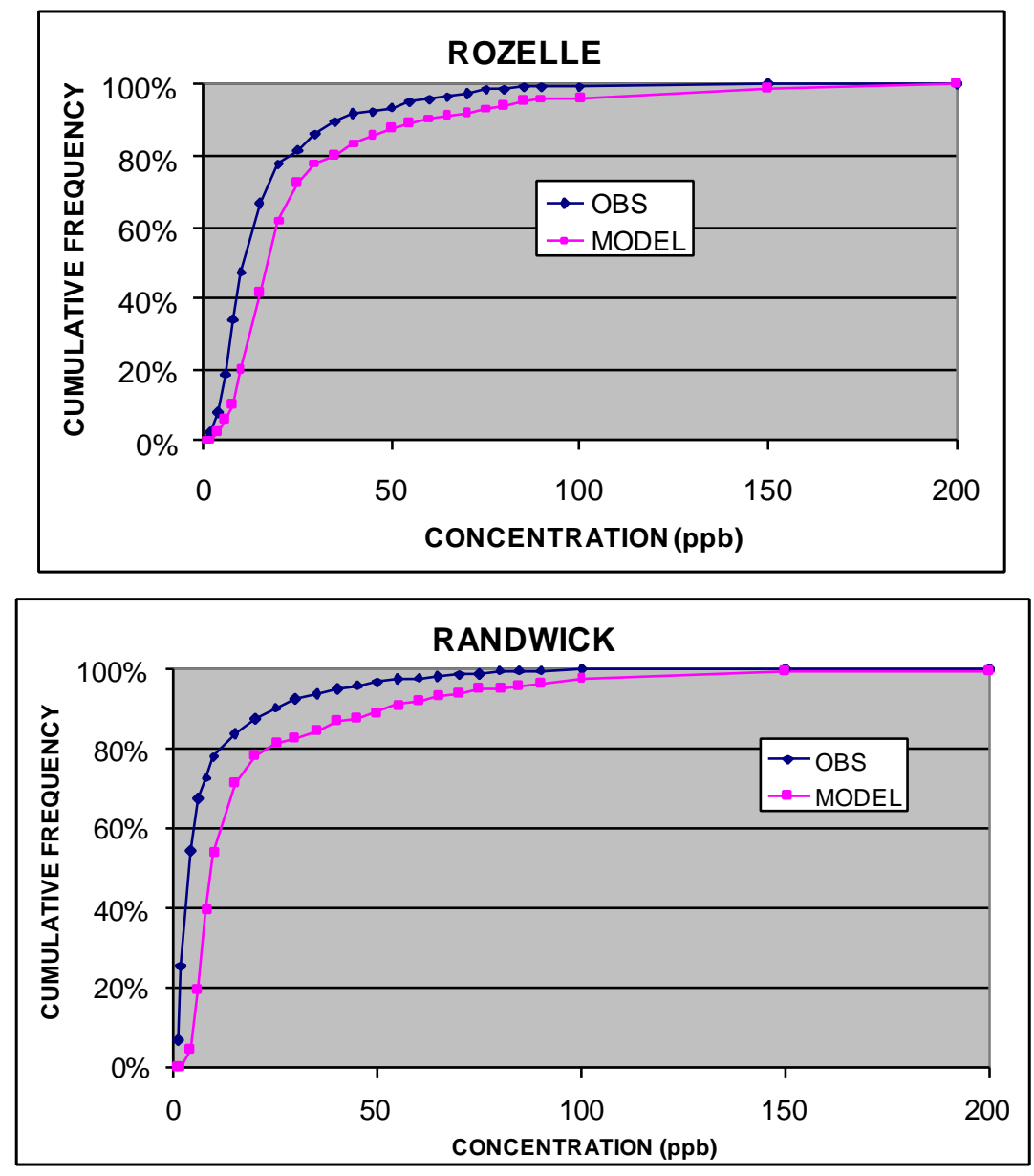
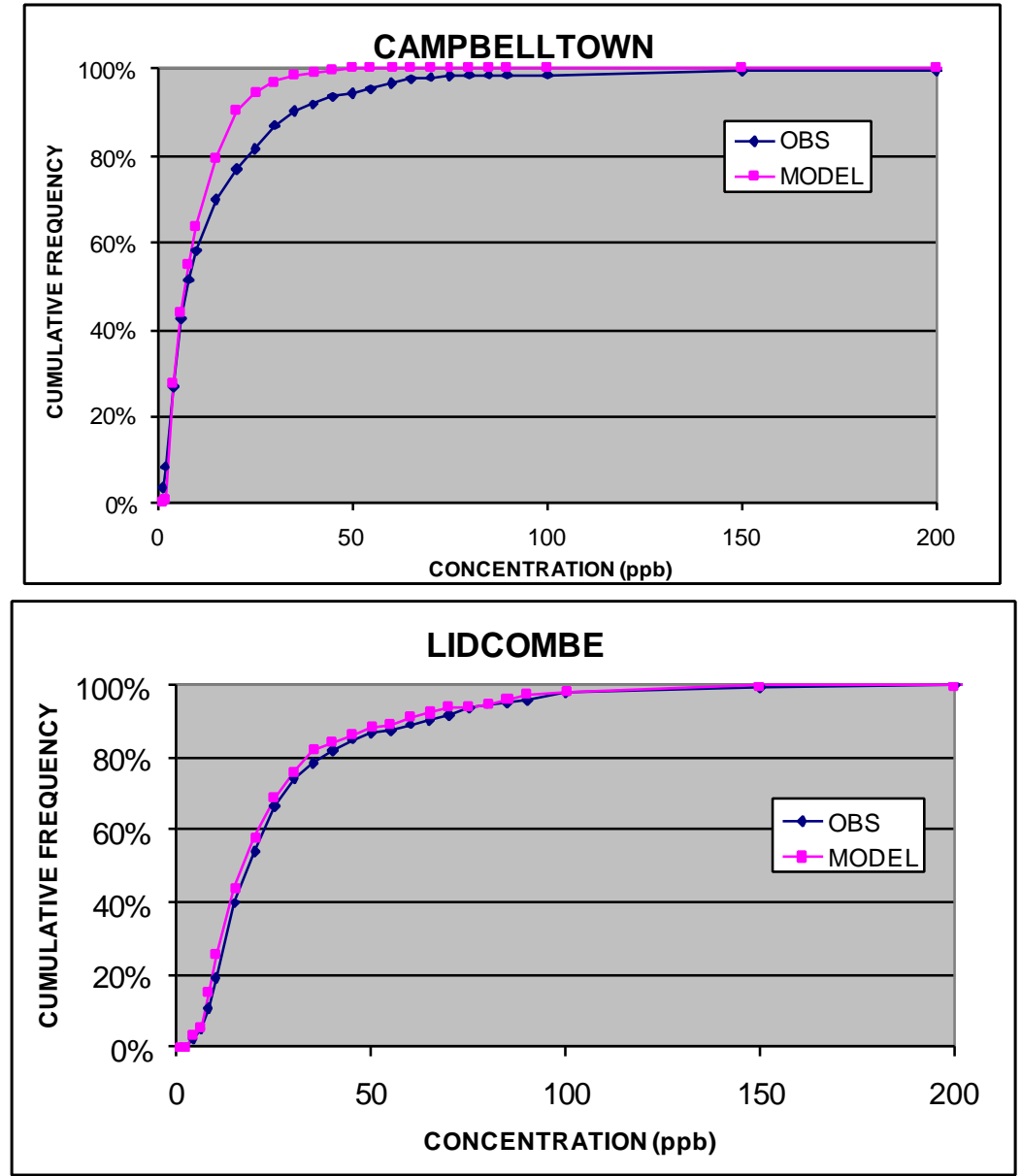

Figure 16: Cumulative frequency distributions of observed and forecast 1-hour ground-level concentrations of $\mathrm{NO}_{\mathrm{x}}$ for selected EPANSW monitoring stations for the month of January 2000 (approximately 600 hours of data per plot). 


\section{Description of the Project}

The primary objective of the Air Quality Forecasting System for Australia's Major Cities Project is to set up, validate, and trial for a four month demonstration period, a real time software system capable of providing accurate air quality forecasts to the public for the purpose of "preventing, combating, or rectifying" the level of air pollution, particularly on forecast high pollution days.

After the Australian Air Quality Forecasting System (AAQFS) is demonstrated in Sydney and Melbourne, the Commonwealth shall have the exclusive right to use the System in Australia for Air Quality Forecasting and will have a non-exclusive right to use the System overseas for the same purpose.

The System will be completed and demonstrated to the public in Sydney in time to provide air quality forecasts for the 2000 Olympic Games. The demonstrations in Sydney and Melbourne need not necessarily be run simultaneously.

The AAQFS comprises the following components:

(i) The "access system", which manipulates

- emissions data based on traffic and industry activity for a particular region from pollution inventories,

- meteorological data from the Limited Area Prediction System (LAPS), being a system developed by the Bureau of Meteorology,

- other materials necessary for the development of the System,

(ii) The "customised airshed system", being the consolidated airshed model that will be customised for a particular region or city,

(iii) A "visual graphics modelling system", which offers a visual graphics representation of the forecasts suitable for the world wide web.

\section{Management Structure and Responsibilities}

The AAQFS is being developed with funding from the Air Pollution in Major Cities

Program, and was approved by the Minister for the Environment as one of the Clear the Air projects on 15 May 1998. The Project is legally organised as a contract between the Commonwealth and CSIRO Atmospheric Research, with subcontracts to other participants. However, the actual conduct of the Project is by a collaborative arrangement as follows:

Bureau of Meteorology Research Centre (BMRC) is responsible for the preparation of the LAPS model for the Project and for the consolidation of various air pollution emissions and chemical transport components to make up the full System. BMRC is providing the resources of the Bureau to access verification data, trialing the System in its various forms and is working with the EPAs to set up information streams to the EPAs from the System. BMRC also is working with CSIRO and the EPAs to develop the visualisation systems.

Environment Protection Authority (Victoria) is providing expertise in developing a real-time emissions inventory system in collaboration with CSIRO, is working with 
EPA NSW to prepare the Sydney emissions inventory for the Project, and is providing an extended emissions inventory for Victoria. EPA (Victoria) is also providing data for validation purposes from the Melbourne monitoring network.

Environment Protection Authority of NSW is providing data for validation purposes from the Sydney monitoring network, is working with EPA (Victoria) in preparing the Sydney emissions inventory for the System, and is facilitating the introduction of the System into Sydney.

CSIRO Energy Technology is underpinning CSIRO Atmospheric Research in the Project by contributing to extensions of the air pollution modelling components, is developing an advanced version of their chemical reaction scheme for high speed smog forecasts, and is developing and providing advanced algorithms for the real-time calculation of vehicle emissions that depend on power requirements, and which in turn depend on hilly terrain - a characteristic of many cities, particularly Sydney.

CSIRO Atmospheric Research is assisting and advising EPA (Victoria) in the development of the real-time emissions inventory, is developing, extending and customising the air pollution modelling component, is working with BMRC to incorporate the air pollution components into the LAPS model, and is participating with the EPAs and BMRC in the development of graphical outputs.

The Project is managed by Dr Peter Manins of CSIRO Atmospheric Research. He chairs the Steering Committee that meets every two months or more often as necessary. The Steering Committee is made up of representatives of the collaborators.

\section{Schedule}

As specified in the contract between the Commonwealth and CSIRO, the Project is in seven phases, with reporting required within 30 days of completion of the phase. The phases are described in the table below.

\begin{tabular}{|l|l|l|l|}
\hline Phase & Tasks & $\begin{array}{l}\text { Date } \\
\text { commenced }\end{array}$ & $\begin{array}{l}\text { Date } \\
\text { completed }\end{array}$ \\
\hline $\begin{array}{l}\text { Phase } \\
\text { Trial a working test system in Melbourne, determine areas of } \\
\text { concern and devise requirements for extension, verification } \\
\text { measures, criteria }\end{array}$ & May 1999 & Jun 1999 \\
\hline $\begin{array}{l}\text { Phase } \\
2\end{array}$ & $\begin{array}{l}\text { Recast latest emissions inventory for Melbourne (Mar 99) into } \\
\text { form for the System. First pass at extending inventory to } \\
\text { respond to weather, events. Trial full prototype system in } \\
\text { Melbourne, test performance }\end{array}$ & Jun 1999 & Jul 1999 \\
\hline $\begin{array}{l}\text { Phase } \\
\text { Extend real-time emissions inventory methodologies to } \\
\text { Sydney, incorporating the new power-based vehicle emissions } \\
\text { application. }\end{array}$ & $\begin{array}{l}\text { May 1999 } \\
\text { Install full prototype System in Sydney and verify against } \\
\text { measures and data. }\end{array}$ & Dec 1999 & \\
\hline
\end{tabular}




\begin{tabular}{|c|c|c|c|}
\hline Phase 4 & $\begin{array}{l}\text { Iterate on performance measures for forecasts for Sydney and } \\
\text { Melbourne, finalise extensions to meteorology component, } \\
\text { incorporate advanced GRS smog model, commence } \\
\text { development of display systems and other products in } \\
\text { consultation with users }\end{array}$ & Jul 1999 & Apr 2000 \\
\hline $\begin{array}{l}\text { Phase } \\
5\end{array}$ & $\begin{array}{l}\text { Demonstration to EPAs of prototype System in Melbourne } \\
\text { and Sydney over summer period. Fix problems and refine } \\
\text { display products in consultation with users in Sydney and } \\
\text { Melbourne }\end{array}$ & $\operatorname{Jan} 2000$ & Jun 2000 \\
\hline $\begin{array}{l}\text { Phase } \\
6\end{array}$ & $\begin{array}{l}\text { Demonstrate full System in Sydney and Melbourne with } \\
\text { products to EPA NSW and EPA VIC for dissemination to } \\
\text { media }\end{array}$ & Jun 2000 & Sep 2000 \\
\hline $\begin{array}{l}\text { Phase } \\
7\end{array}$ & $\begin{array}{l}\text { Package outputs for EPAs in light of demonstrations. } \\
\text { Document performance, validate against System performance } \\
\text { measures and recommend extensions }\end{array}$ & Oct 2000 & May 2001 \\
\hline
\end{tabular}

